\title{
Recommendations based on Social Links
}

\author{
Danielle Lee ${ }^{1}$ and Peter Brusilovsky ${ }^{2}$ \\ ${ }^{1}$ Sangmyung University \\ Department of Software \\ 1460-1 Bangbae-dong Seocho-gu, Seoul, 06568, Korea \\ suleehs@gmail.com \\ ${ }^{2}$ School of Information Sciences, University of Pittsburgh, \\ 135 North Bellefield Ave., Pittsburgh, PA 15260, USA \\ peterb@pitt.edu
}

\begin{abstract}
The goal of this chapter is to give an overview of recent works on the development of social link-based recommender systems and to offer insights on related issues and the future direction. Among several branches of social recommendations, specifically, this chapter focuses on recommendations, which are founded on users' self-defined (i.e., explicit) social links and target to suggest desirable items, not social links of interests. This chapter provides a brief overview over the technical needs for social link-based recommendations and the studies explaining the viability of users' social networks as useful information sources from a social science point of view. Then, the in-depth understanding of existing recommendations based on users' social links will be addressed. Lastly, various issues and future directions of social link-based recommendation research are put forward.
\end{abstract}

\subsection{Introduction}

The remarkable popularity of social media encourages web users to participate in various online activities and to generate data on an unprecedented scale. Given exponentially growing social media data volumes, personalized recommendation technologies have proven the effectiveness as a solution of the information overload problem; have offered positive user experiences with more relevant contents; and have presented competitive advantage to the social media business [119]. As predictive analysis of online users' tastes, recommendation technology adaptively filters out unnecessary data and selectively chooses presumably favorable information according to users' preferences. At odds with the original principle of personalized recommendations, which is to give users control of information access, however, the typical and most popular collaborative filtering recommendation technology performs all steps autonomously and allows no room for users to get involved in information personalization of their own. The lacking user involvement causes several problems 
(illustrated in Section 12.3.1), and many researchers have called attention to solutions to improve the quality of typical recommendation technology and to cope with the relevant problems. Among the several streams of research to develop the solutions, one important evolution is to take advantage of users' self-defined online social networks and proposes to generate recommendations based on users' social links social link-based recommendations. The idea to utilize users' online social links as a foundation of recommendation is undoubtedly spurred by the recent phenomenon of online social networks.

Compared with the era when web users stayed in isolation, a number of social media systems have been adapting online sociability, helping users to find people of interest, and as well as encouraging them to socially associate with people of interest. In fact, web users' active and eager participation on social media are intrinsically motivated by not only personal desire for information management and knowledge acquisition but also social desire for engagement and communication with their people [95]. Online users have been participating in social media as an essential part of their everyday lives and share numerously resources with their social links, for instance, movies to watch, books to read, academic papers to refer to, bookmarks to explore, music concert to enjoy, etc. Online social links provide a rich source of useful information and knowledge and in turn, are used to propagate various kinds of information [138]. According to prominent social science theories - homophily and social influence introduced in Section 12.3.2 - we have a strong tendency to associate and bond with others who are similar to us, and are affected by our social links. It causes changes of our attitudes, beliefs and behavioral propensities [22]. In seeking useful sources to enrich users' information preference model and to acquire desirable information for personalized recommendations, several researchers often have considered users' online social links. Therefore, central to this chapter is to give a general description of existing social link-based recommendation technologies and to discuss the related problems.

More specifically, the focus of this chapter lies on recommendations, which are founded on users' self-defined (i.e., explicit) social links and target to suggest desirable items, not social links of interests. Because social recommendations is actively evolving field of research, depending on the purpose of each study, researchers have been investigating social recommendation technologies in various ways. For instance, the studies constituting 'social recommendations' include recommenders to utilize implicitly inferred social links as its foundations of recommendations; to suggest person(s) to be connected (as introduced in Chapter 16 [16]); or to recommend items to a group of users (For more detailed explanations about various kinds of social recommendations, refer to section 12.2). Through personalized recommendations of items based on users' explicit social networks, we will examine how researchers harness the power of users' various social interactions and the resultant social phenomenon (e.g. information influence, homophily, information cascade, etc.) in personalizing users' information spaces and substantiate the importance of online explicit social networks as information source.

The rest of the chapter is organized as following: Section 12.2 systematically reviews various ways to employ online social networks for personalized recommendations. The next Section discusses the challenges of traditional collaborative filtering technology and provides rationale for using online social links 
as feasible information source. Sections 12.4 and 12.5 provide an overview of multiple aspects of social link-based recommendations including algorithms. Section 12.6 discusses other issues related to social link-based recommendations.

\subsection{A Range of Definitions of Social Recommendations}

Given widely ranging definitions of social recommendation studies, before we embark on a discussion of social link-based recommendations, it is worth taking a look at various streams of the related research and necessary to more clearly limit the scope of social link-based recommendation technologies to be considered in this chapter. Because personalized recommendations on social media is the currently evolving matter [113], existing works have studied this topic in diverse ways. For instance, one direction of research focuses on generating recommendations of information items, while another direction focuses on recommending people to connect with or groups to join. The kinds of social networks used in recommendations also vary; ranging from explicit social connections among humans to artificial networks of intelligent machines. Considering the target information of recommendation and the types of social links used for recommendation, we could classify social recommendation research into the following five directions.

- Item recommendation using users' explicit (i.e. self-defined) social links

- Item recommendation using users' implicit social links

- Recommendations of trustworthy communication partners (i.e. machines) using artificial links

- People recommendation

- Item recommendation without social links

The studies belonging to the first direction exploited social links explicitly created by target users as the foundations for their recommendations. The explicitly defined social connections are important because the connections develop social phenomena through social interactions, as introduced in the previous section. That is, once users establish social connections explicitly, they tend to pay attention to their partners' online activities. Hence, users are easily affected by their social connections. Then, recommender systems are able to take advantage of social interactions and the resultant social phenomena in personalization processes. The typical collaborative filtering recommendations assume that the roles of all users in a recommender system are equal, in turn, 'role uniformity [121].' However, generating recommendations and accepting the suggestions is decision making process. Every user has different interests, knowledge, and especially different social context and social roles. For this reason, target users (i.e. recipients of recommendations) expect transparent explanations about where the recommended information comes from. This chapter mainly focuses on this kind of social recommendations.

As the second kind, there are several recommendation studies based on users' implicit social links. Implicit social connections mean that user-to-user links are inferred by users' various online interactions (e.g. reviewing same products, commenting on same items, befriending with similar group of people, etc.) and 
derived from mathematical calculations such machine learning. Put differently, depending on the kind of machine learning method, users' social partners will be changed. Thus, the choice of machine learning methods and the details are the major determinants of the users' implicit social networks. Lumbreras \& Gavaldà [77], Pitsilis \& Knapskog [99] and Victor, et al. [126] belong to this kind of recommendations. A practical reason why the researchers chose the implicit social networks instead of explicit ones is the lack of available data sources (which consist of users' favourite items and their social connections). Since the researchers have a difficulty to find eligible data, they simply created their own using machine learning methods. Even though it is getting better, the data sources available for social linkbased recommendations are still limited.

The studies belonging to the third direction are focusing on how to select reliable communication partners (i.e. computer agent) to exchange information from one machine to another machine, not to take advantage of social links among human beings. Depending on how one machine is trustworthy to another machine, the researchers interpreted machine-to-machine connections as a trust-based network, and computed how the trust values are inferred and propagated. Lam [69] and Shi, et al. [108] are the examples.

The fourth recommendation approach aims to suggest people of interest, instead of favourable information items or products. The recommended people could be a male/female to date $[2,68,100]$, a person to befriend with $[36,4]$, or a colleague to work with $[135,75]$. Chapter $16[16]$ offers a thorough review of people recommendation.

Lastly, there are some studies just borrowed the terminology from 'social recommendations'. The technologies of the studies are traditional collaborative filtering or content-based recommendations without any social context. They are nothing to do with online social networking. Since the works took into account data sources provided by social media and utilized collective intelligent mechanisms, the authors simply called their technologies as social recommendations. Bellogin \& Parapar [9], Debnath, et al. [30], Diaz-Aviles, et al. [34], Messenger \& Whittle [89], Pazos Arias, et al. [97], Sanchez, et al. [103], Yoon, et al. [140], Zhou, et al. [145] and Ziqi, et al., [147] are the examples.

Even though we did not include them in the list, 'group/online community-based recommendation' consists of another critical research stream in social recommendation technology. While the area of recommender systems originally ignored a group of users, more recent research in this topic paid close attentions to users' groups. Group-based recommendations aggregate preferences of a group of people and suggesting recommendations to a whole group, not an individual member [20]. For example, once users enter a room, Flytrap identifies each of them via RFID, aggregates all their preferences together, computes the probabilistic values of all songs for recommendations and finally plays music for people in the same physical space [24]. Other existing group-based recommendation suggested TV programs or movies to watch to a whole family $[59,64]$, venues and routes to travel together [26], restaurants to enjoy together [96], points of interest based on users' visited locations [129], recipes to cook for a family [10] or a community to join $[3,131]$.

In summary, we limit the main body of this chapter to the studies satisfying four criteria - 1) they should suggest items of interests; 2) the target recipients of their 
recommendations should be individual users; 3 ) the personalization should take into account the opinions of users' social networks; and 4) users should explicitly define their social networks.

\subsection{Background}

\subsubsection{Challenges of the Traditional Collaborative Filtering Recommendations}

Collaborative filtering is currently the most popular among several core recommendation technologies. Envisioned originally as 'word-of-mouth' automation [107], it starts with finding a neighborhood of likeminded users (known as peers) who have similar interests to a target user (i.e. a recipient of recommendations) and then recommends items favored by the peers to the target user. An extensive review of rating-based collaborative filtering can be found in Chapter 10 of this book [61]. The inherent ability of collaborative filtering to harness ratings of multiple automatically identified peers (who are not even known to the target user) gives this technology an impressive power, while also serving as a source of several recognized problems [11].

The first problem is a striking vulnerability of collaborative filtering to shilling attacks and copy-profile attacks. In order to reinforce their own ratings and intentionally distort recommendation predictions toward their aiming directions, a malicious user can create multiple bogus user profiles and insert fake user-item ratings. It will give them a capability to promote or defame a certain product. It is referred to as 'shilling attack' $[48,148,143]$. A malicious user who wants to wickedly affect recommendations given to a specific user, can create very similar rating profiles by copying the specific user's ratings. Naturally, a collaborative recommender system will pick these malicious users as perfect peers and any new items positively rated by these peers will be highly recommended to the specific user [87]. It is known as the 'copy-profile attack'.

The second problem is known as the 'cold-start user problem' $[23,87]$. It refers to a situation when recently joined users have not yet rated enough items. In this situation, recommender systems can't comprehend users' preferences reliably and can't generate quality recommendations. A similar problem known as the 'gray sheep problem' affects users with eccentric taste (so called 'gray sheep users'). Since these users have low taste similarity with other users, collaborative recommenders might not be able to find useful peers for a grey sheep user even with a considerable number of ratings [114].

Many collaborative filtering systems are also affected by 'data-sparsity problem' $[11,94]$. When the number of items in a system is relatively higher than the number of users, user-item rating matrix is too sparse to find sufficient number of co-rated items among users. In particular, data sparsity makes it hard to use collaborative filtering in cases when items have a short life cycle (e.g. job openings, events, or news articles). These items might simply have too little time to accumulate enough ratings before their values expire and user-item rating distribution is usually sparse. Finally, classic 
collaborative filtering incurs high computational costs because it compares one target user's taste with the tastes of all other users [113].

The problems reviewed above stem from one of the two core principles of collaborative filtering: the automatic selection of anonymous peers based on rating similarity. Consequently, one way to resolve these problems could be to unlock the black box peer selection hidden from recipient users of recommendations and to enable users to participate in their recommendation process. Recommendations based on users' self-defined social links could be considered as a step in this direction.

\subsubsection{Online Social Networks: A Useful Source of Information}

The idea to utilize users' social links as information source for their recommendations is based on two preeminent theories about sociality - homophily and social influence.

Homophily explains that people tend to make social connections with other people who possess similar characteristics with them, for instance, age, sex, religion, ethnicity, educational and occupational class, social positions, etc., in a process of 'social selection' [28]. Traditional homophily-related research explored offline social networking and focused on the similarity of people's personal characteristics and social status (i.e. status homophily) [22]. In contrast, the research on homophily in online social networking context focused on homophily in online social networking context focused on homophily according to users' perceived values and internal knowledge states (i.e. value homophily). Friedkin [40] suggested that the desire to be connected to the similar people stems from tendency to use those who are similar to us as a reference group and compare ourselves with the references to get information or make a decision. Besides, due to the ease of communication, shared knowledge and other factors which make the interactions comfortable, people are more likely to construct social connections with similar people than dissimilar people $[134,88]$.

Whereas homophily explains how and why people select their social partners, social influence explains how people's various aspects are affected by their social links. Social influence represents a situation where people' attitudes, beliefs, and behavioral propensities are affected by and adopted to their social ties [28]. Deutsch and Gerard [32] distinguished social influences into two distinct processes according to the expected results of the influences - normative influence and informational influence. Normative influence is a tendency to conform to the positive expectation of their friends or group members with social desire to be a member of a social group or to seek social approval. This desire is intimately connected to psychological burden and, time and again, the influence transforms into coercive compulsion and compliance [146]. Meanwhile, informational influence refers to "an influence to accept information from another as (trustworthy) evidence about objective reality $[124$, p.35]." This type of influence is evoked by ambiguity and uncertainty of reality. When people are not sure about an accurate view of reality and whether they are acting in a right way or not, they seek conformity from other people who are similar and have expertise and credibility [125]. In the context of online social networks which are frequently used as a source of new information, information influence becomes critical since it influences users' ability to collect accurate and useful information. Hence, the choice of social links is critical to social media users. In the 
modern connected world, users become more and more knowledgeable how to make the choices of social partners as useful information sources. Furthermore, the information side of social influence is one of the reasons why social capital is so valuable and why viral marketing on social media works [27,37].

The cumulative studies have demonstrated an interplay between homophily and social influence in social networks. For instance, when two socially associated people are alike, their reciprocal influence is stronger and longer than it is for a pair less similar to each other [39]. Brzozowski et al [19] empirically proved the homophily and social influence of three kinds of social connections - friends, allies and foes. The study was performed using data of an online forum where users share opinions and vote on various controversial political topics (resolves). In this context, both social ties and users' ideologies are important to consider. In this paper, friends are based on personal familiarity (i.e. strong ties) while allies do not necessarily have personal acquaintances but share similar ideologies (i.e. weak ties). Foes are the ones who a user doesn't ideologically agree with (i.e. negative tie). The authors examined which resolves users vote on and how they vote. They found that, when users voted on a certain resolve, their friends are more likely to vote on the same resolve than allies and foes. Interestingly, users tend to avoid resolves that their foes already voted on. However, users voted in more similar pattern with their allies than with their friends or foes. Of course, users agreed the least with their foes [19]. We interpreted these results to mean that all of the three ties played certain roles as social filters. Friends and foes are important in the choice of items to consider and allies are important to decide how to vote.

Baartarjav, et al. [7] presented an exemplary study demonstrating homophily in online space, in particular online groups. In this study based on Facebook data, the authors focused on the personal traits of online group members such as age, gender, religion, living area, political opinions, etc. They built clusters solely based on these traits and found distinguishable characteristics of each group. Depending on the discovered characteristics, they recommended a group to join and their recommendation accuracy was $73 \%$ on average. Therefore, similar people get socially associated as co-members of the same group [7].

Several studies explored social influences in social media applications. Singla and Richardson [109] tested co-relationship between instant messenger logs and the similarity of search queries. Search interests of people who exchanged instant messages frequently were more similar than interests of random pairs. Moreover, the longer they communicated, the more similar they were. Swamynathan, et al. [117] compared the influence on users' satisfaction depending on different social identities of transaction partners. Specifically, they focused on an online auction site Overstock auction. In the system, users can have two kinds of relations - their personal connections (friends) and business connections (once a user buys a product, the seller becomes a business connection). The authors found that users bought products mostly from total strangers - only $2 \%$ of transactions were made between two friends who are directly connected. However, users evaluations showed that they are much more likely to be satisfied with the transactions made with personal connections than with their business connections or strangers. In addition, the degree of satisfactions was decreased along with the increase of social distance [117]. 


\subsection{Multiple Dimensions of Social Link-based Recommendations}

With the purpose to systematically analyze and classify various social link-based recommendations, we identified six dimensions as shown on Figure 12.1.

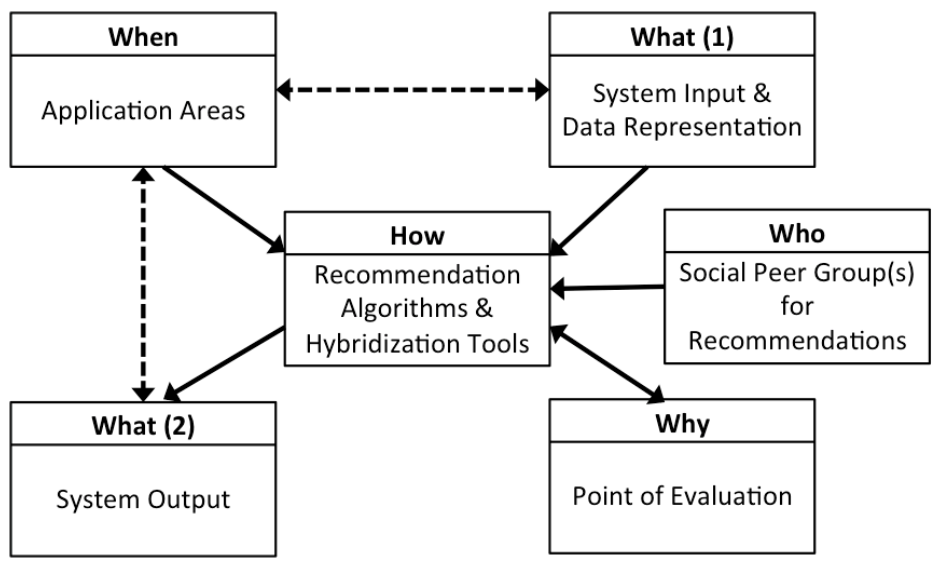

Fig. 12.1. Various Dimensions of Social Link-based Recommendations

(The solid lines denote direct interactions with recommendation algorithms and the dotted lines represent indirect association with recommendation algorithms.)

- The first dimension is what kind of data is used as a source for personalization and in which format the input data was represented. It identifies the kinds of input data the recommender system utilized and how the data was interpreted as user preference models.

- The kind of input data is directly related to target items and applications of the recommendation technologies. The second dimension is what item was recommended. It classifies the sorts of output items that each study targeted.

- The next third dimension is to explore when social network-based recommendations are used. The dimension identifies several applications in which social link-based recommendation technologies were deployed or tested.

- The fourth dimension is who the social peers were on which the recommendations were built. The review identified the kinds of social networks used as the foundations of recommendations. We also discussed why each type of social network was used in recommendations.

- The fifth dimension is how the recommendations can be generated. We explore this dimension in two perspectives - the kind of recommendation algorithms and whether and how multiple algorithms were hybridized.

- The last dimension is why the recommendation technology was assessed. Among various evaluation criteria of recommendations, the review finds in which aspect each study assessed its' proposed social link-based recommendations. 
The arrow lines of Figure 12.1 show the flows of data. Recommender systems receive user data input (i.e. what (1)) and social links used in recommendations (i.e. who) from applications (i.e. when). Once the recommendation computation is done (i.e. how), the systems produce target items (i.e. what (2)). Depending on the results assessed by points of evaluations (i.e. why), recommender systems update their recommendation algorithms and procedures iteratively to optimize the performance.

We analyzed the existing social link-based recommendation approaches according to the dimensions, as Table 12.1 and Table 12.3 show. Particularly, Table 12.1 summarizes the distribution of the existing approaches from the first dimension till the fourth dimension, whereas Table 12.3 is intended to provide the overview of the existing approaches mainly on the perspective of recommendation algorithms (fifth dimension) and the evaluation methods (sixth dimension).

Table 12.1. Data inputs and the representation, the kinds of social networks, target items, and application areas of the existing social link-based recommendation approaches

(This table includes prominent approaches, thus implying that not every social link-based recommendation study is included. When a research team published a series of studies with similar approaches, we grouped them together as one approach)

\begin{tabular}{|c|c|c|c|c|}
\hline Approaches & $\begin{array}{l}\text { Input and Data } \\
\text { Representation }\end{array}$ & $\begin{array}{l}\text { Kinds of } \\
\text { Social } \\
\text { Networks }\end{array}$ & $\begin{array}{l}\text { Target } \\
\text { Items }\end{array}$ & $\begin{array}{l}\text { Systems/Data } \\
\text { Sources }\end{array}$ \\
\hline \multicolumn{5}{|c|}{ Recommendations based on Trust Networks } \\
\hline $\begin{array}{l}\text { Al-Sharawneh } \\
\& \text { Williams [5] }\end{array}$ & $\begin{array}{c}\text { Numeric user-to-item } \\
\text { ratings \& users' trust } \\
\text { statements }\end{array}$ & $\begin{array}{l}\text { Trust-based } \\
\text { network }\end{array}$ & $\begin{array}{l}\text { General } \\
\text { Products }\end{array}$ & Epinions.com \\
\hline $\begin{array}{c}\text { Chen, et al., } \\
\text { [23] }\end{array}$ & $\begin{array}{c}\text { Numeric user-to- } \\
\text { review ratings \& users' } \\
\text { trust/distrust } \\
\text { statements }\end{array}$ & $\begin{array}{l}\text { Trust-based } \\
\text { network }\end{array}$ & $\begin{array}{l}\text { Reviews to } \\
\text { Refer to }\end{array}$ & Epinions.com \\
\hline $\begin{array}{c}\text { Chia \& Pitsilis } \\
\text { [25] }\end{array}$ & $\begin{array}{l}\text { Numeric user-to-item } \\
\text { ratings \& users' trust } \\
\text { statements }\end{array}$ & $\begin{array}{l}\text { Trust-based } \\
\text { network }\end{array}$ & $\begin{array}{l}\text { General } \\
\text { Products }\end{array}$ & Epinions.com \\
\hline $\begin{array}{l}\text { Deng, et al. } \\
\quad[31]\end{array}$ & $\begin{array}{l}\text { Numeric user-to-item } \\
\text { ratings \& users' trust } \\
\text { statements }\end{array}$ & $\begin{array}{l}\text { Trust-based } \\
\text { network }\end{array}$ & $\begin{array}{l}\text { General } \\
\text { Products }\end{array}$ & Epinions.com \\
\hline $\begin{array}{l}\text { Golbeck, et al. } \\
{[42,44,43]}\end{array}$ & $\begin{array}{l}\text { Numeric user-to-item } \\
\text { ratings \& users' } \\
\text { numeric trust } \\
\text { statements }\end{array}$ & $\begin{array}{l}\text { Trust-based } \\
\text { network }\end{array}$ & Movies & FilmTrust \\
\hline $\begin{array}{c}\text { Jamali \& Ester } \\
{[52,53]}\end{array}$ & $\begin{array}{l}\text { Numeric user-to-item } \\
\text { ratings \& users' trust } \\
\text { statements }\end{array}$ & $\begin{array}{l}\text { Trust-based } \\
\text { network }\end{array}$ & $\begin{array}{l}\text { General } \\
\text { Products }\end{array}$ & Epinions.com \\
\hline $\begin{array}{c}\text { Jamali \& Ester } \\
\text { [54] }\end{array}$ & $\begin{array}{l}\text { Numeric user-to-item } \\
\text { ratings, users' trust } \\
\text { statements or the list of } \\
\text { users' friends }\end{array}$ & $\begin{array}{l}\text { Trust-based } \\
\text { networks \& } \\
\text { Friendship }\end{array}$ & $\begin{array}{l}\text { 1) General } \\
\text { Products } \\
\text { 2) Movies }\end{array}$ & $\begin{array}{l}\text { 1) Epinions.com } \\
\text { 2) Flixster }\end{array}$ \\
\hline Ma, et al. [78] & $\begin{array}{l}\text { Numeric user-to-item } \\
\text { ratings \& users' trust } \\
\text { statements }\end{array}$ & $\begin{array}{l}\text { Trust-based } \\
\text { networks }\end{array}$ & $\begin{array}{l}\text { General } \\
\text { Products }\end{array}$ & Epinions.com \\
\hline
\end{tabular}




\begin{tabular}{|c|c|c|c|c|}
\hline Approaches & $\begin{array}{l}\text { Input and Data } \\
\text { Representation }\end{array}$ & $\begin{array}{l}\text { Kinds of } \\
\text { Social } \\
\text { Networks }\end{array}$ & $\begin{array}{l}\text { Target } \\
\text { Items }\end{array}$ & $\begin{array}{l}\text { Systems/Data } \\
\text { Sources }\end{array}$ \\
\hline Ma, et al. [80] & $\begin{array}{l}\text { Numeric user-to-item } \\
\text { ratings \& users' trust } \\
\text { statements }\end{array}$ & $\begin{array}{l}\text { Trust-based } \\
\text { networks }\end{array}$ & $\begin{array}{l}\text { General } \\
\text { Products }\end{array}$ & Epinions.com \\
\hline Ma, et al. [81] & $\begin{array}{l}\text { Numeric user-to-item } \\
\text { ratings, the users' trust } \\
\text { statements or the list of } \\
\text { users' friends }\end{array}$ & $\begin{array}{l}\text { Trust-based } \\
\text { networks \& } \\
\text { Friendship }\end{array}$ & $\begin{array}{l}\text { 1) General } \\
\text { Products } \\
\text { 2) Movies }\end{array}$ & $\begin{array}{l}\text { 1) Epinions.com } \\
\text { 2) Douban }\end{array}$ \\
\hline $\begin{array}{c}\text { Massa \& } \\
\text { Avesani [86] }\end{array}$ & $\begin{array}{l}\text { Numeric user-to-item } \\
\text { ratings \& users' trust } \\
\text { statements }\end{array}$ & $\begin{array}{l}\text { Trust-based } \\
\text { network }\end{array}$ & $\begin{array}{l}\text { General } \\
\text { Products }\end{array}$ & Epinions.com \\
\hline $\begin{array}{l}\text { Moradi, et al. } \\
{[93]}\end{array}$ & $\begin{array}{l}\text { Numeric user-to-item } \\
\text { ratings \& users' trust } \\
\text { statements }\end{array}$ & $\begin{array}{l}\text { Trust-based } \\
\text { networks \& } \\
\text { Friendship }\end{array}$ & $\begin{array}{l}\text { 1) General } \\
\text { Products } \\
\text { 2) Movies }\end{array}$ & $\begin{array}{l}\text { 1) Epinions.com } \\
\text { 2) FilmTrust }\end{array}$ \\
\hline $\begin{array}{c}\text { Moradi \& } \\
\text { Ahmadian [92] }\end{array}$ & $\begin{array}{c}\text { Numeric user-to-item } \\
\text { ratings \& users' trust } \\
\text { statements } \\
\end{array}$ & $\begin{array}{c}\text { Trust-based } \\
\text { networks \& } \\
\text { Friendship } \\
\end{array}$ & $\begin{array}{l}\text { 1) General } \\
\text { Products } \\
\text { 2) Movies } \\
\end{array}$ & $\begin{array}{l}\text { 1) Epinions.com } \\
\text { 2) FilmTrust }\end{array}$ \\
\hline $\begin{array}{l}\text { Symeonidis, et } \\
\text { al. [118] }\end{array}$ & $\begin{array}{l}\text { Numeric user-to-item } \\
\text { ratings, the users' trust } \\
\text { statements or the list of } \\
\text { users' friends }\end{array}$ & $\begin{array}{l}\text { Trust-based } \\
\text { network \& } \\
\text { Friendship }\end{array}$ & $\begin{array}{l}\text { 1) General } \\
\text { Products } \\
\text { 2) Movies }\end{array}$ & $\begin{array}{l}\text { 1) Epinions.com } \\
\text { 2) Flixster }\end{array}$ \\
\hline $\begin{array}{l}\text { Victor, et al. } \\
{[127]}\end{array}$ & $\begin{array}{c}\text { Numeric user-to-item } \\
\text { ratings \& users' trust } \\
\text { statements }\end{array}$ & $\begin{array}{l}\text { Trust-based } \\
\text { networks }\end{array}$ & $\begin{array}{l}\text { General } \\
\text { Products }\end{array}$ & Epinions.com \\
\hline $\begin{array}{l}\text { Wang, et al. } \\
\text { [132] }\end{array}$ & $\begin{array}{l}\text { Numeric user-to-item } \\
\text { ratings, the users' trust } \\
\text { statements or the list of } \\
\text { users' friends }\end{array}$ & $\begin{array}{l}\text { Trust-based } \\
\text { network \& } \\
\text { Friendship }\end{array}$ & $\begin{array}{l}\text { 1) General } \\
\text { Products } \\
\text { 2) Movies } \\
\text { 3) Movies, } \\
\text { books, and } \\
\text { music }\end{array}$ & $\begin{array}{l}\text { 1) Epinions.com } \\
\text { 2) Flixster } \\
\text { 3) Douban }\end{array}$ \\
\hline $\begin{array}{l}\text { Yang, et al. } \\
\text { [137] }\end{array}$ & $\begin{array}{l}\text { Numeric user-to-item } \\
\text { ratings \& users' trust } \\
\text { statements }\end{array}$ & $\begin{array}{l}\text { Trust-based } \\
\text { Network }\end{array}$ & $\begin{array}{l}\text { General } \\
\text { Products }\end{array}$ & Epinions.com \\
\hline $\begin{array}{l}\text { Yuan, et al. } \\
\text { [142] }\end{array}$ & $\begin{array}{l}\text { Numeric user-to-item } \\
\text { ratings \& users' trust } \\
\text { statements }\end{array}$ & $\begin{array}{l}\text { Trust-based } \\
\text { Network }\end{array}$ & $\begin{array}{l}\text { General } \\
\text { Products }\end{array}$ & Epinions.com \\
\hline \multicolumn{5}{|c|}{ Recommendations based on friendship networks } \\
\hline $\begin{array}{c}\text { Bellogín, et al. } \\
{[8]}\end{array}$ & $\begin{array}{l}\text { Numeric user-to-item } \\
\text { ratings \& the list of } \\
\text { users' friends } \\
\end{array}$ & Friendship & Movies & Filmtipset \\
\hline $\begin{array}{c}\text { Bonhard, et al. } \\
{[14]}\end{array}$ & $\begin{array}{l}\text { Users' demographic } \\
\text { profile, numeric user- } \\
\text { to-item ratings \& the } \\
\text { list of users' friends }\end{array}$ & Friendship & Movies & MovieMatch \\
\hline $\begin{array}{l}\text { Carrer-Neto, et } \\
\quad \text { al. [21] }\end{array}$ & $\begin{array}{l}\text { Binary user-to-item } \\
\text { ratings (like/dislike), } \\
\text { various types of } \\
\text { metadata of movies \& } \\
\text { the list of users' }\end{array}$ & Friendship & Movies & $\begin{array}{l}\text { Experimented with } 10 \\
\text { student participants \& } \\
\text { Movies Metadata } \\
\text { from IMDB }\end{array}$ \\
\hline
\end{tabular}




\begin{tabular}{|c|c|c|c|c|}
\hline Approaches & $\begin{array}{l}\text { Input and Data } \\
\text { Representation }\end{array}$ & $\begin{array}{c}\text { Kinds of } \\
\text { Social } \\
\text { Networks }\end{array}$ & $\begin{array}{l}\text { Target } \\
\text { Items }\end{array}$ & $\begin{array}{l}\text { Systems/Data } \\
\text { Sources }\end{array}$ \\
\hline & friends & & & \\
\hline $\begin{array}{c}\text { De Meo, et al } \\
{[29]}\end{array}$ & $\begin{array}{l}\text { Numeric user-to-item } \\
\text { ratings \& list of users' } \\
\text { friends }\end{array}$ & $\begin{array}{l}\text { Friendship } \\
\text { among } \\
\text { College } \\
\text { Students } \\
\end{array}$ & Movies & $\begin{array}{l}\text { Executed experiment } \\
\text { with } 37 \text { college } \\
\text { student participants }\end{array}$ \\
\hline $\begin{array}{c}\text { Groh \& Ehmig } \\
{[46]}\end{array}$ & $\begin{array}{l}\text { Numeric user-to-item } \\
\text { ratings \& list of users' } \\
\text { friends }\end{array}$ & Friendship & $\begin{array}{l}\text { Local Night } \\
\text { Clubs }\end{array}$ & Lokalisten \\
\hline $\begin{array}{c}\text { Gürsel and Sen } \\
{[49]}\end{array}$ & $\begin{array}{l}\text { Users' social tags and } \\
\text { comments on items \& } \\
\text { the list of users' } \\
\text { friends }\end{array}$ & Friendship & Photos & Flickr \\
\hline $\begin{array}{l}\text { Jiang, et al. } \\
{[56]}\end{array}$ & $\begin{array}{l}\text { Content of various } \\
\text { information items (e.g. } \\
\text { blogs/microblogs, } \\
\text { photos, videos) and the } \\
\text { sharing records within } \\
\text { users' social networks } \\
\& \text { the list of users' } \\
\text { reciprocal or } \\
\text { unidirectional social } \\
\text { links }\end{array}$ & $\begin{array}{l}\text { Friendship } \\
\text { and } \\
\text { Unidirectional } \\
\text { relations }\end{array}$ & $\begin{array}{l}\text { 1) Blogs, } \\
\text { photos and } \\
\text { video links } \\
\text { 2) } \\
\text { Microblogs }\end{array}$ & $\begin{array}{l}\text { 1) Renren } \\
\text { 2) Tencent Weibo }\end{array}$ \\
\hline $\begin{array}{l}\text { Knijnenburg, et } \\
\text { al. [63] }\end{array}$ & $\begin{array}{l}\text { Facebook users' } \\
\text { "likes" records on } \\
\text { music artists \& the list } \\
\text { of users' friends }\end{array}$ & Friendship & Music Artists & $\begin{array}{l}\text { Experimented with } \\
267 \text { Facebook users, } \\
\text { and the test bed } \\
\text { system was a } \\
\text { Facebook music } \\
\text { recommender system }\end{array}$ \\
\hline $\begin{array}{c}\text { Konstas, et al. } \\
{[65]}\end{array}$ & $\begin{array}{l}\text { Users' music play- } \\
\text { counts, users' tags and } \\
\text { the list of their friends }\end{array}$ & Friendship & Music & Last.fm \\
\hline $\begin{array}{c}\text { Liu and Lee } \\
{[76]}\end{array}$ & $\begin{array}{l}\text { Numeric user-to-item } \\
\text { ratings \& list of users' } \\
\text { friends }\end{array}$ & Friendship & $\begin{array}{l}\text { Digital Items } \\
\text { for Personal } \\
\text { websites }\end{array}$ & $\begin{array}{l}\text { Experimented with } 27 \\
\text { users of a Korean SNS } \\
\text { (Cyworld) and their } \\
\text { online friends. }\end{array}$ \\
\hline $\begin{array}{c}\text { Sinha \& } \\
\text { Swearingen } \\
{[111]}\end{array}$ & $\begin{array}{l}\text { Numeric user-to-item } \\
\text { ratings \& the list of } \\
\text { users' friends }\end{array}$ & Friendship & $\begin{array}{l}\text { 1) Books } \\
\text { 2) Movies }\end{array}$ & $\begin{array}{l}\text { Executed this study } \\
\text { with } 19 \text { student } \\
\text { participants and } \\
\text { system-oriented } \\
\text { recommendations } \\
\text { came from the } \\
\text { following sources; } \\
\text { 1) Amazon, Sleeper \& } \\
\text { RatingZones for } \\
\text { books and } \\
\text { 2) Amazon, Reel.com, } \\
\text { \& MovieCritics for } \\
\text { movies }\end{array}$ \\
\hline Wang, et al. & Users' check-in & Friendship & Locations of & Brightkite and \\
\hline
\end{tabular}




\begin{tabular}{|c|c|c|c|c|}
\hline Approaches & $\begin{array}{l}\text { Input and Data } \\
\text { Representation }\end{array}$ & $\begin{array}{c}\text { Kinds of } \\
\text { Social } \\
\text { Networks }\end{array}$ & $\begin{array}{l}\text { Target } \\
\text { Items }\end{array}$ & $\begin{array}{c}\text { Systems/Data } \\
\text { Sources }\end{array}$ \\
\hline$[130]$ & $\begin{array}{c}\text { records of visited } \\
\text { locations \& the list of } \\
\text { users' friends }\end{array}$ & & Interests & Gowalla \\
\hline \multicolumn{5}{|c|}{ Recommendations based on other types of social networks } \\
\hline Guy, et al. [50] & $\begin{array}{l}\text { Users' tags, } \\
\text { bookmarks, comments, } \\
\text { organizational charts, } \\
\text { the list of users' online } \\
\text { friends and various } \\
\text { working activities. }\end{array}$ & $\begin{array}{l}\text { Professional } \\
\text { colleagues (in } \\
\text { various } \\
\text { working } \\
\text { contexts) and } \\
\text { online friends }\end{array}$ & $\begin{array}{l}\text { Internet or } \\
\text { Intranet } \\
\text { pages of } \\
\text { interests, } \\
\text { blogs, and } \\
\text { communities }\end{array}$ & $\begin{array}{l}\text { Experimented with } \\
290 \text { subjects, and the } \\
\text { test bed system was a } \\
\text { social application } \\
\text { suite for a company }\end{array}$ \\
\hline $\begin{array}{c}\text { Lee \& } \\
\text { Brusilovsky } \\
{[71,74]}\end{array}$ & $\begin{array}{l}\text { Users' bookmarks and } \\
\text { their group } \\
\text { membership }\end{array}$ & $\begin{array}{c}\text { Watching } \\
\text { Network (i.e. } \\
\text { Directed } \\
\text { Network) \& } \\
\text { Group } \\
\text { membership }\end{array}$ & $\begin{array}{l}\text { Academic } \\
\text { articles }\end{array}$ & Citeulike \\
\hline $\begin{array}{c}\text { Macedo, et al. } \\
{[82]}\end{array}$ & $\begin{array}{c}\text { Users' event } \\
\text { attendance records, } \\
\text { context information of } \\
\text { events, and the list of } \\
\text { users' groups }\end{array}$ & $\begin{array}{c}\text { Group } \\
\text { Membership }\end{array}$ & $\begin{array}{l}\text { Regional } \\
\text { Events }\end{array}$ & Meetup.com \\
\hline Sun, et al. [116] & $\begin{array}{l}\text { Users' bookmarks, the } \\
\text { social tags \& list of } \\
\text { users' groups }\end{array}$ & $\begin{array}{c}\text { Group } \\
\text { Membership }\end{array}$ & $\begin{array}{l}\text { Internet } \\
\text { pages of } \\
\text { interests }\end{array}$ & Delicious \\
\hline $\begin{array}{c}\text { Yuan, et al., } \\
{[141]}\end{array}$ & $\begin{array}{l}\text { List of users' favorite } \\
\text { artists \& the list of } \\
\text { users' friends and } \\
\text { groups }\end{array}$ & $\begin{array}{l}\text { Group } \\
\text { membership } \\
\text { \& friendship }\end{array}$ & Music Artists & Last.fm \\
\hline $\begin{array}{c}\text { Zhang, et al., } \\
{[144]}\end{array}$ & $\begin{array}{l}\text { Users' friends and } \\
\text { followers \& activities } \\
\text { of users' social links } \\
\text { on social media }\end{array}$ & $\begin{array}{l}\text { Friendship \& } \\
\text { following } \\
\text { network }\end{array}$ & $\begin{array}{l}\text { Social Links } \\
\text { Online } \\
\text { Activities }\end{array}$ & $\begin{array}{l}\text { Social links and the } \\
\text { online activity } \\
\text { information from } \\
\text { Facebook and Twitter } \\
\& \text { experimented with } \\
10 \text { participants }\end{array}$ \\
\hline
\end{tabular}

\subsubsection{Input Data Types of Social Link-based Recommendations}

As a typical collaborative filtering scenario, there are users $U \in\left\{u_{1}, u_{2}, \ldots, u_{n}\right\}$ and items $I \in=\left\{i_{1}, i_{2}, \ldots, i_{l}\right\}$. Each user $u$ has a set of items $I_{u}$ on which he some form of opinion (known also as feedback). $r_{u i}$ denotes the user $u$ 's opinion on an item $i_{l}$. The $r_{u i}$ can be explicit, implicit, or descriptive as Table 12.2 shows.

Table 12.2. Various Indications of Users' Opinions

\begin{tabular}{|l|l|l|l|}
\hline \multicolumn{2}{|c|}{ Input Type } & \multicolumn{2}{c|}{ Eescription } \\
\hline Explicit & Unary & Like & Bookmarks and 'Like' on \\
\hline
\end{tabular}




\begin{tabular}{|l|l|l|l|}
\hline Opinion & & \multicolumn{1}{|c|}{} & Facebook \\
\cline { 2 - 4 } & Binary & Like or dislike & $\begin{array}{l}\text { Thumb up or thumb down on } \\
\text { YouTube }\end{array}$ \\
\cline { 2 - 3 } & 5um or 10 Likert Scales & Movie ratings \\
\hline Implicit Opinion & $\begin{array}{l}\text { No predetermined value } \\
\text { ranges. Ranges from zero } \\
\text { to maximum number of } \\
\text { instances. }\end{array}$ & $\begin{array}{l}\text { Purchases, play-counts of } \\
\text { videos and songs, click- } \\
\text { through and check-in records } \\
\text { of a location }\end{array}$ \\
\hline Descriptive Opinion & $\begin{array}{l}\text { No predetermined value } \\
\text { ranges or text values. }\end{array}$ & $\begin{array}{l}\text { Social tags, movie } \\
\text { descriptions, } \\
\text { descriptions. }\end{array}$ \\
\hline
\end{tabular}

Explicit opinion is usually directly expressed by the user within a scale that is defined by the system and can range from coarse to fine-grained. Unary explicit feedback such as Facebook-style 'like' buttons is on the coarse-grained side. Another example of a coarse-grained unary feedback is a bookmark. A bookmark expresses user's interest in an item, however, the absence of the bookmark does not necessarily tell that he is not interested. A binary rating allows to clearly separate likes and dislikes from unrated items. A more finer-grained ratings can be expressed using a numeric rating scale. Most typical are scales 1 5 or 1 10 (i.e. 1 usually indicates 'dislike a lot' and 5 or 10 means 'like a lot') [105]. Systems also collect user activity data from various sources to implicitly infer users' interests. Implicit indicators do not have clear value ranges. We cannot predict how many times a uses purchased a product or how many times a user listened to a song. Hence, the implicit indications often require normalization of the values. For more detailed explanations about explicit and implicit data types, see also Chapter 14 [55].

Out of 36 approaches in Table 12.1, most of them (24 studies, 66.6\%) used numeric ratings and six approaches used unary ratings based on bookmarks or binary ratings. Six approaches used implicit indications. For instance, to recommend locations of interest, Wang, et al. [130] utilized users' check-in records of visited locations and the timestamps and Konstas, et al. [65] used users' music play-counts to recommend a song to enjoy.

Explicit and implicit preferences show whether and how much a user is interested in an item. However, relatively simple coarse-grained ratings or implicit preferences do not carry enough useful information. To add more direct information about users' preferences, some studies used extra textual indications showing the reasons of a user's interests or how he understands an item. Carrer-Neto, et al. [21] borrowed movie-related metadata from IMDB and combined it with users' binary ratings. In this way, they enriched the users' binary preferences into multi-dimensional preferences. Macedo, et al. [82] considered not only users' event attendance records but also various contextual information of events such as topics of events, the locations, and the temporal information. Sun, et al. [116] and Lee \& Brusilovsky $[71,74]$ used social tags to improve the quality of bookmark-based recommendations. Bonhard, et al. [14] took advantage of users' demographic information to recommend movies to watch. 


\subsubsection{Applications and Target Items of Social Link-based Recommendations}

The type of social links used by personalized recommenders to a considerable extent depends on the applications (i.e., a specific social system) and the target items that this application recommends. Fig. 12.2 and Fig. 12.3 review the item types that social link-based recommendations have targeted and applications that engage in social linkbased recommendations.

Figure 12.2 shows that social link-based recommendations most often focus on recommending general products. The popularity of "general products" category is defined by the position of Epinions.com ${ }^{1}$ system as the most heavily used source of data for social link-based recommendations (see Figure 12.3): among 18 studies based on trust-based networks, 17 studies used Epinions.com data sets (see Table 12.1 and Figure 12.3). The popularity is caused by the fact that this is the first publicly available data source containing not only user-to-item ratings but also user-to-user explicit social relations. Several versions of Epinions.com data set have been used in social link-based recommendation studies and, as of 2015, three versions of dataset are available online ${ }^{2,3}$ The former two data sets are collected and shared by Paolo Massa's team [85]. The first version contains about 49K users, $139 \mathrm{~K}$ items, 664K ratings and $487 \mathrm{~K}$ trust-based relations, whereas the second version contains larger volume of data $(132 \mathrm{k}$ users, $1.6 \mathrm{M}$ items, $13.7 \mathrm{M}$ review sand $841 \mathrm{~K}$ relations). The difference of the data volume aside, the users' ratings of the second version are about other users' reviews, not about items. In addition, the positive trust relations constitute the trust network in the first data set but the second data includes both positive and negative trust relations. Among 18 studies based on trust-based networks at Table 12.1, Al-sharawneh \& Williams [5], Chia \& Pitsilis [25], Deng, et al. [31], Jamali \& Ester [52,53], Moradi, et al. [92,93], Symeonidis, et al. [118], Victor, et al. [127], Wang, et al. [132] and Yuan, et al. [141] used the first Epinions.com dataset, while one study [23] used the second dataset. The third Epinions.com dataset is collected and shared by Pedro Domingos' team [102]. It has large number of users and items $(71 \mathrm{~K}$ users, $104 \mathrm{~K}$ items, $571 \mathrm{~K}$ user-to-item ratings and more than $500 \mathrm{~K}$ trust-based relationships). Jamali \& Ester [54] and Yang, et al. [137] also used this dataset.

\footnotetext{
${ }^{1}$ Epinions.com aims to review a wide range of products from digital gadgets, appliances, sports gears, toys, movies, books, songs and more. None of the studies using Epinions.com datasets clearly stated the product category of the target items; hence we classified the target items as general products.

${ }^{2}$ http://www.trustlet.org/wiki/Epinions_dataset

${ }^{3}$ http://alchemy.cs.washington.edu/data/epinions/
} 


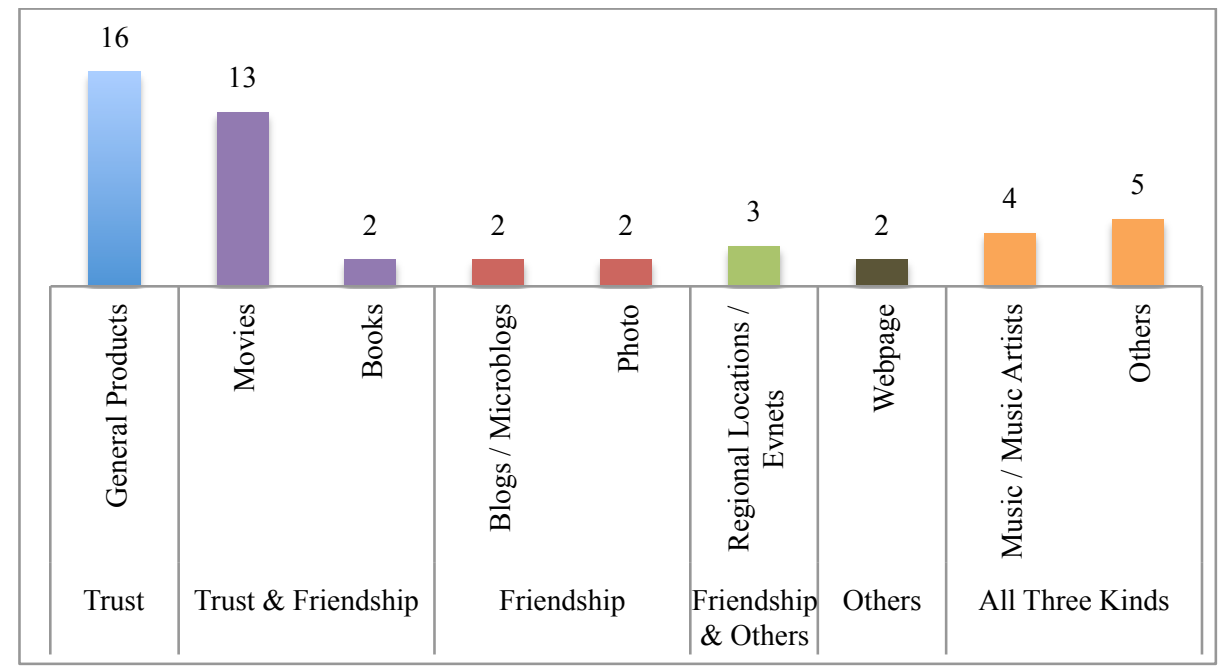

Fig. 12.2. Types of Target Items in Social Link-based Recommendations (some applications data provides several types of items)

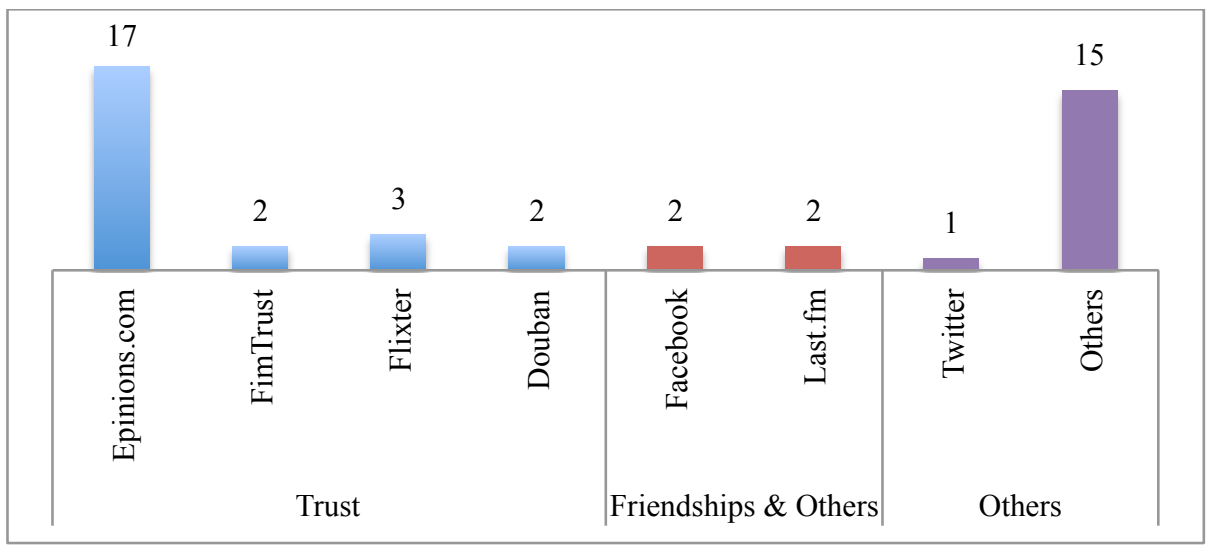

Fig. 12.3. Data Sources of Social Link-based Recommendations (some studies used several data sources)

Movies, the second-most popular type of target items, have the longest history as a target of recommendations. The early pioneer recommender system, MovieLens, publicly shared the data set has been used in a number of recommendations-related studies and still does. The popularity of movies as the target items of personalized recommendations has been further increased by the Netflix Prize ${ }^{4}$. Researchers took advantage of various data sources for social link-based movie recommendations: FilmTrust [42-44,92,93] ${ }^{5}$, Flixster [54,118,132], Douban ${ }^{6}$ [81,132], Filmtipset [8],

\footnotetext{
${ }^{4} \mathrm{http} / / / \mathrm{www}$. netflixprize.com

${ }^{5} \mathrm{http}: / / \mathrm{www}$. librec.net/datasets.html
} 
MovieMatch [14], IMDB [21], Amazon.com, Reel.com and MovieCritics [111]. Since some of these systems used trust links and some use friendship links, thus both of these link types have been explored as a source of data to recommend movies.

Music or music artists recommendations explored the value of several types of social links; trust-based, friendship-based and group-membership-based. Douban [132], Last.FM [65,141] and Facebook [63] were used as a context for music recommendations. Last.FM is a social music website. In this system, users are able to listen to music, add tags and make friendship with other users as well. Several Last.FM datasets are available with and without the social network information ${ }^{7,8,9}$. Music is a challenging type of items to generate precise recommendations because user feedback is highly subjective. However, our music taste is influenced by our social connection, and we often share our favorite songs with our friends. In this context, recommendation approaches based on social links can provide valuable insights for music or music artist recommendations.

Another two related types of target items that could benefit from using social lnks for recommendation are places of interest (POI) and events. Locations and events to visit are inherently social. When we want to enjoy a Friday night at a local restaurant or go to a music concert, we invite out friends or family to go along. In one of the pioneering works, Wang, et al. [130] has explored how to recommend places of interests via users' check-in locations and their online social networks. The authors started their study by proving the positive correlation between users' online social connections and their visiting records, and found that a considerable number of users visited locations, which their friends or friends-of-friends have visited before. In their study based on Random Walk with Restart algorithm, they demonstrated that when users make a decision to visit a place, the information about whereabouts of their online friends could reinforce the quality of personalized POI recommendations. Groh \& Ehmig [46] utilized friendship information to recommend local night clubs. Their results showed that recommendations based on friends' data are better than the suggestions based on traditional anonymous peers. A few years ago, Yelp, a social system for finding and rating local businesses (such as restaurants, bars, coffee shops, etc.), announced a recommendation challenge ${ }^{10}$. A number of researchers have participated in the challenge, and several rounds of evaluations have been completed. However, the work focused on recommending POIs such as restaurants or coffee shops using online social connections are still rare. Some of this work is reviewed in the Chapter 16 of this book [16].

Overall, the review of target item types and application for which social links were explored as a source of information for recommendation demonstrates that the work in this area is distributed quite unevenly. While there is a large concentration of work for some types of items where research data are officially released as a dataset or can be crawled (such as research based on Epinions.com datasets), other systems and item types received too little attention. Interesting, that the amount of research in the

\footnotetext{
${ }^{6} \mathrm{http}: / / \mathrm{dl}$. dropbox.com/u/17517913/Douban.zip

${ }^{7} \mathrm{http} / / /$ www.dtic.upf.edu/ ocelma/MusicRecommendationDataset/lastfm-1K.html

${ }^{8} \mathrm{http} / / /$ labrosa.ee.columbia.edu/millionsong/lastfm

${ }^{9} \mathrm{http}: / /$ socialcomputing.asu.edu/datasets/Last.fm

${ }^{10} \mathrm{http}: / /$ www.yelp.com/dataset_challenge
} 
context of a specific social system is not quite correlated with its popularity. For example, some highly popular social media systems such as Facebook and Twitter have rarely been used to explore the role of social links for recommendations. It may be due to the difficulty to crawl large volume of data on the applications and the wide diversity of items. In Table 12.1, two studies using Facebook or Twitter [144,63] evaluated the quality of link-based recommendations with relatively small groups of human subjects.

\subsubsection{Types of Social Connections Employed in Link-Based Recommendations}

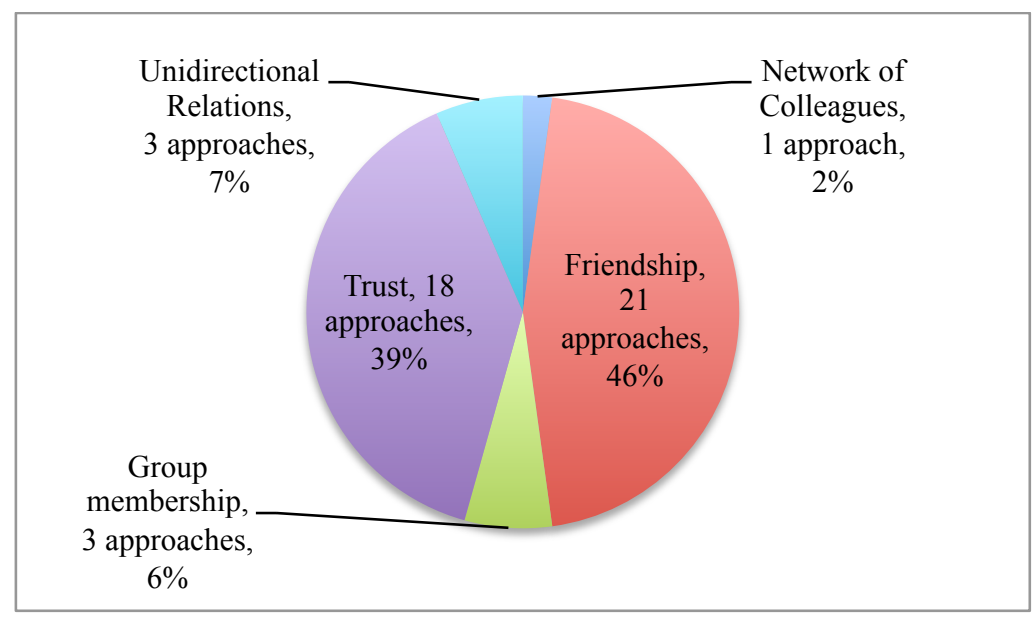

Fig. 12.4. Types of Social Links Employed in Personalized Recommendations (Some approaches were based on more than one kind of social networks)

Figure 12.4 groups the work on social link-based recommendations reviewed in Table 12.1 by the type of social links used to generate recommendations. It shows that trust networks and friendship connections are the most popular social links to provide personalized access to information.

Trust is an asymmetric relationship. When a user $u$ trusts another user $v$, the trusted user $v$ does not necessarily trust user $u$. In this aspect trust is different from friendships which require mutual agreement on the relationship, the user $v$ does not need to approve user $u$ 's trust or reciprocally trust the user $u$. Besides, the trusting party (i.e., the user $u$ ) can state how much their trusted parties (i.e. the user $v$ ) are trustworthy. The trust relationship also enables users to define negative relations (distrust), by using negative trustworthiness values. Golbeck suggested that, while the traditional definition of 'trust' is lexically related to security and reliability, 'social trust' in the Web 2.0 era is the broader definition of trust and is related to 'a matter of opinion and perspective'. Hence, information can be aggregated, sorted and filtered through social trust [41]. Based on this suggestion, in the series of her studies, Golbeck demonstrated that users prefer recommendations from trusted parties to traditional collaborative filtering recommendations $[42,44,43]$. 
Friendship is a reciprocal relationship. Compared with other types of online social connections introduced in this chapter, friendship is highly relying on personal familiarity. Personal familiarity is a foundation, on which many friendships are rooted, in particular friendships existing offline. According to homophily and social influence theories introduced at the Section 12.3.2, it is well-known that "strong ties" who engage in frequent interactions and have many overlapping connections tend to be similar in various ways. Friendship-based recommendations actively use this social pattern.

The remaining social connections are unidirectional relations, group memberships and network of colleagues. Wellman suggested that, in Web 2.0 era, various new 'less bounded' online relationships would emerge [133]. Following relationship is a typical example of the newly emerging online social networks. The typical examples of this relationship include "following" on Twitter, "watching" on CiteULike, "network" on Delicious or "following" on Google plus. Users on the Web 2.0 have found it easier to know who knows what through social media. However, it is a burden to contact people who possess the desired knowledge via their personal ties [60]. Many social bookmarking systems, which help users to manage and share interesting information, as well as blogging systems, which aim to post online journals to express their opinions, offer users this special kind of online sociability without any need to ask a consent to be followed. Once users find other users whose information collections are useful, they are allowed to follow or watch the users' activities continuously. The relationships do not require any offline interactions or any mutual agreements for being connected. Some studies $[70,72,73]$ have provided the positive evidence that the relations met the similarity attraction hypothesis [90] and held transitivity power [91]. High degree of similarity was embedded in following relations and the similarity decreased with the increase of distance. It means that users in unidirectional relations built their connections focusing on their objects of interest. As a result, these kinds of social networks could be classified as object-centered social networks. Breslin and Decker said that the social links connecting users via items of interests may be more long-lived than the relationships not sharing any item of interest [18].

Group membership is a social connection established between users who are members of the same online group or community. It is typically a highly objectcentered social association, since group activities are usually centered on a certain topic. An online group is usually a community of interest or practice, for instance, a fan club of a musician, a community of Hadoop programmers, an online forum for students taking the same course, and an online space for members of the same project. Users engaged in group-based networks target to distribute topic relevant information or contribute topic-relevant activities. The theory of communal sharing explains the social dynamics of group membership. Group members think they share common substances. Before online social networks emerged and proliferated, the communal sharing relationships represented close relationships such as kinship ties [38]. In the current Web 2.0 era where relationships are getting flattened and less bounded, however, the sense of communal sharing can be applied to online group activities. Group members treat information objects as their shared assets and are willing to share what they need or contribute what they can. They usually do not expect to receive something back in return for their contributions. In addition, members do not pay attention to the portion of contributions made by each individual member. Being a 
member of a group is sufficient to them since they are able to use the resources the group is sharing [38]. Therefore, membership of an online group is informative in understanding users' information needs and personalizing their information space.

Overall, the analysis of social link types used in social link-based recommendations shows that the work is distributed quite unevenly. The dominated majority of work is focused on just two types of connections. Among the studies listed in Table 12.1, more than $85 \%$ of them are based on either trust networks or friendship. Moreover, as indicated above, almost all works on trust-based networks reviewed in Table 12.1 used the Epinions.com data set with one exception (Golbeck, et al. $[42,44,43])$. Considering a wide variety of online sociability, we believe that more work should be focused on proving the expandability of social link-based recommendations to more diverse and less explored social networks as well as new applications and domains.

Finally, our review shows that early works of social link-based recommendations was focused on an assumption that our social links have equal influence over us. However, recent works demonstrated that the reality is more sophisticated - different types social links have difference degree of influence. As a way to take into account this inequality, researchers distilled various social properties in social link-based recommendations. For example, Arazy, et al. [6] suggested to distinguish four kinds of social properties - the degree of homophily, tie strength (the frequency of interactions), trust and reputation - and integrated these properties into the nearest neighbor-based social link-based approach. Although the proposed approach is a conceptual framework without any empirical evaluation of the performance, it provided meaningful insights about how to incorporate various social network properties in personalized recommendations. Another type of social property - social influence - has been used in social link-based recommendations. In order to include the property as a part of social link-based recommendation algorithm, for instance, Jiang et al. [56] computed the degree of social influence by considering social association (i.e. whether a given pair of two users are friends or one user followed another user) and the distribution of items shared between two given users. In particular, because the data sources of this study do not contains users' numeric/binary ratings for items, the authors relied on content of items and estimated the social influence at the level of topical distributions of each item. Gürsel and Sen [49] consider the unequal influence of our friends on different topics of interest in producing recommendations. Chia, et al. [25] took advantage of 'experience level' of social connections as an extra social property in personalized recommendations, with an intuition that we are more likely to seek advices from others who more experienced than us. The authors defined the experience level by combining explicit trust statements and the numbers of rated items.

\subsection{Algorithms for Social Link-based Recommendations}

A unique feature of social recommendation algorithms is the engagement of social connections to generate or enhance recommendations. Understanding different approaches that could be used to leverage social links for recommendation is most 
critical to those who would like to understand or to develop social recommendation approaches. This section attempts to combine three goals: explain most important types of social link-based recommendation algorithms in sufficient details, classify existing research on social link-based recommendation from the prospect of employed algorithms, and provide representative examples of using each major algorithm type. We classified the algorithms used for social link-based recommendations according to the Tang and Liu's classification of traditional approaches [120] with one specific addition - direct friend-to-friend recommendations. The classification includes the nearest neighbour approaches, graph structure-based approaches, matrix factorization and hybrid recommendations. Table 12.3 reviews existing research on social linkbased recommendations from the prospect of employed algorithms and the evaluation criteria. Figure 12.5 offers a visual summary of the algorithms and their use in reviewed works.

As mentioned above, a major motivation for social link-based recommendations was to solve various problems of collaborative filtering by substituting or complementing anonymous like-minded peers used in traditional collaborative filtering with explicitly defined social connections of the target user. Therefore, most of the social link-based recommendations use one of traditional collaborative filtering algorithms as a basis and modify it to improve the quality of recommendation by infusing social links. As Figure 12.5 depicts, the most popular algorithms are the nearest neighbour-based approaches and matrix factorization, which are also widely used in collaborative filtering. Due to this tight connection between traditional collaborative filtering and social link-based recommendations, Chapter 10 of this book [61], which reviews classic rating-based collaborative filtering, could be a useful background reading for this chapter. Yet the presentation below is designed to be selfcontaining.

Table 12.3. Descriptions of Recommendation Algorithms and the Evaluation Criteria (This table includes prominent approaches, thus implying that not every social link-based recommendation study is included. When a research team published a series of studies with similar approaches, we grouped them together as one approach)

\begin{tabular}{|c|c|c|}
\hline Approaches & Description of Recommendation Algorithms & $\begin{array}{c}\text { Evaluation } \\
\text { Criteria } \\
\end{array}$ \\
\hline \multicolumn{3}{|c|}{ Trust Network-based Recommendations } \\
\hline $\begin{array}{l}\text { Al-Sharawneh } \\
\text { \& Williams } \\
{[5]}\end{array}$ & $\begin{array}{l}\text { Nearest Neighbor-based Recommendations: Authors } \\
\text { defined global credibility values of users by combining } \\
\text { their trustworthiness and expertise. The credibility is } \\
\text { intended to identify global opinion leaders, and, at the } \\
\text { final stage to compute the rating predictions, credibility } \\
\text { values of leaders were multiplied to the probability } \\
\text { values, which were calculated by the nearest neighbor } \\
\text { algorithm of conventional collaborative filtering. }\end{array}$ & MAE \\
\hline $\begin{array}{l}\text { Chen, et al., } \\
{[23]}\end{array}$ & $\begin{array}{l}\text { Clustering-based Recommendations: } \\
\text { based on users' ratings, the authors } \\
\text { constructed clusters and within each cluster, } \\
\text { they identify experts using reputation scores. } \\
\text { The reputation scores were computed by the }\end{array}$ & $\begin{array}{l}\text { Coverage rate, } \\
\text { MAE, } \\
\text { computational } \\
\text { time, precision, } \\
\text { recall and F- }\end{array}$ \\
\hline
\end{tabular}




\begin{tabular}{|c|c|c|}
\hline Approaches & Description of Recommendation Algorithms & $\begin{array}{c}\text { Evaluation } \\
\text { Criteria }\end{array}$ \\
\hline & $\begin{array}{l}\text { PageRank algorithm of trust-based networks. } \\
\text { Among the identified experts, distrusted ones } \\
\text { were excluded. Then using a cluster which is } \\
\text { highly related to a candidate item and a target } \\
\text { user's ratings, recommendation probability was } \\
\text { computed. }\end{array}$ & measure \\
\hline $\begin{array}{l}\text { Chia \& } \\
\text { Pitsilis [25] }\end{array}$ & $\begin{array}{l}\text { Nearest Neighbor-based Recommendations: Authors } \\
\text { used various sorting tactics - information similarity, } \\
\text { experience level and trustworthiness - in selecting target } \\
\text { users' social peers. Once they chose different groups of } \\
\text { social peers, conventional Pearson correlation-based } \\
\text { rating predictions were applied (refer to the Eq. } 3 \text { ). }\end{array}$ & $\begin{array}{l}\text { MAE, precision, } \\
\text { recall, F-measure } \\
\text { and coverage }\end{array}$ \\
\hline $\begin{array}{l}\text { Deng, et al. } \\
{[31]}\end{array}$ & $\begin{array}{l}\text { Graph Structure-based Recommendations: Modified } \\
\text { Random Walk (i.e. RelevantTrustWalker) with trust } \\
\text { relevancy. Instead of random selection of social peers, } \\
\text { each walk is selected according to trust relevancy, which } \\
\text { combines users' trust statements and information } \\
\text { similarities. }\end{array}$ & $\begin{array}{l}\text { RMSE, coverage, } \\
\text { F-measure and } \\
\text { computational time } \\
\text { and cold-start user } \\
\text { problem }\end{array}$ \\
\hline $\begin{array}{l}\text { Golbeck, et al. } \\
{[42,44,43]}\end{array}$ & $\begin{array}{l}\text { Nearest Neighbor-based Recommendations: For a } \\
\text { given candidate item, the authors aggregated raters of the } \\
\text { candidate item, through the Breadth First Search of users' } \\
\text { trust-based networks. In order to propagate unknown } \\
\text { trust values from target users to their indirectly trusted } \\
\text { party, TidalTrust metric was used (refer to eq. } 5 \sim \text { eq. } 7 \text { ). } \\
\text { Explicit and inferred trust values of social peers were } \\
\text { multiplied to peers' ratings on the candidate item }\end{array}$ & $\begin{array}{l}\text { Rating prediction } \\
\text { accuracy (Absolute } \\
\text { difference between } \\
\text { actual ratings and } \\
\text { predicted ratings) }\end{array}$ \\
\hline $\begin{array}{l}\text { Jamali \& } \\
\text { Ester } \\
{[52,53]}\end{array}$ & $\begin{array}{l}\text { Graph Structure-based Recommendations: The } \\
\text { Random Walk of a trusted network and item-based } \\
\text { collaborative filtering with weighted hybridization, so- } \\
\text { called 'TrustWalker' }\end{array}$ & $\begin{array}{l}\text { RMSE, coverage, } \\
\text { F-measure, and } \\
\text { cold-start user } \\
\text { problem }\end{array}$ \\
\hline $\begin{array}{l}\text { Jamali \& } \\
\text { Ester [54] }\end{array}$ & $\begin{array}{l}\text { Matrix Factorization: Matrix Factorization combined } \\
\text { with users' trust-based networks - SocialMF. In } \\
\text { particular, latent feature vectors of users were weighted } \\
\text { by average ratings of users' direct trusted social links. }\end{array}$ & $\begin{array}{l}\text { RMSE and } \\
\text { computational time } \\
\text { and cold-start user } \\
\text { problem }\end{array}$ \\
\hline Ma, et al. [78] & $\begin{array}{l}\text { Matrix Factorization: in matrix factorization, the } \\
\text { authors considered target users' latent factors, } \\
\text { user-to-user trust-based influences }\end{array}$ & MAE \& RMSE \\
\hline Ma, et al. [80] & $\begin{array}{l}\text { Matrix Factorization: The authors applied matrix } \\
\text { factorization technique not only to user-to-item matrix } \\
\text { but also to user-to-user social network. Then, social } \\
\text { factor matrix and the confidence values of trust } \\
\text { statements were incorporated into the training function to } \\
\text { minimize the sum of squared errors }\end{array}$ & MAE \\
\hline Ma, et al. [81] & $\begin{array}{l}\text { Matrix Factorization: Matrix Factorization with two } \\
\text { types of social regularization is to incorporate the tastes } \\
\text { of target users' social links. }\end{array}$ & MAE \& RMSE \\
\hline $\begin{array}{l}\text { Massa \& } \\
\text { Avesani [86] }\end{array}$ & $\begin{array}{l}\text { Nearest Neighbor-based Recommendations: user-to- } \\
\text { user similarities of collaborative filtering were replaced }\end{array}$ & $\begin{array}{l}\text { MAE, MAUE } \\
\text { (Mean Absolute }\end{array}$ \\
\hline
\end{tabular}




\begin{tabular}{|c|c|c|}
\hline Approaches & Description of Recommendation Algorithms & $\begin{array}{c}\text { Evaluation } \\
\text { Criteria }\end{array}$ \\
\hline & $\begin{array}{l}\text { with trust values between users and their direct and } \\
\text { indirect trust-based links. Especially, in order to } \\
\text { propagate unknown trust values from target users to their } \\
\text { indirectly trusted party, MoleTrust metric was used. }\end{array}$ & $\begin{array}{l}\text { User Error), rating } \\
\text { coverage, user } \\
\text { coverage and cold- } \\
\text { start user problem }\end{array}$ \\
\hline $\begin{array}{l}\text { Moradi, et al. } \\
\text { [93] }\end{array}$ & $\begin{array}{l}\text { Clustering of Social Graphs: As the first step, they } \\
\text { found sparse sub-graphs consisting of dissimilar nodes } \\
\text { (i.e. other users) and, as the second step, the nodes were } \\
\text { used as initial centers of clustering algorithm. Once the } \\
\text { system found a fine set of clusters, as the last step to } \\
\text { generate recommendations, the authors computed the } \\
\text { recommendation probabilities of candidate items using a } \\
\text { similar function between a target user and other users in } \\
\text { the target user's cluster. }\end{array}$ & $\begin{array}{l}\text { MAE, RMSE, } \\
\text { precision, recall, F- } \\
\text { measure and } \\
\text { coverage }\end{array}$ \\
\hline $\begin{array}{l}\text { Moradi \& } \\
\text { Ahmadian } \\
{[92]}\end{array}$ & $\begin{array}{l}\text { Nearest Neighbor-based Recommendations: By } \\
\text { combining trust-based social links and anonymous top N } \\
\text { nearest neighbors, they built an initial trust network and } \\
\text { generated a set of recommendations using the Pearson } \\
\text { correlation-based nearest neighbor approach. The authors } \\
\text { applied a reliability measure to the generated } \\
\text { recommendations and when the reliability value did not } \\
\text { exceed a certain threshold, they concluded that the initial } \\
\text { trust network is not a reliable reference for making good } \\
\text { recommendations. Therefore, the authors restructured } \\
\text { trust network. They iterated this network reconstruction } \\
\text { until the reliability value of recommendations exceeds } \\
\text { the predetermined threshold. }\end{array}$ & $\begin{array}{l}\text { MAE, MAUE, item } \\
\text { coverage, user } \\
\text { coverage, cold-star } \\
\text { user problem, } \\
\text { opinionated users, } \\
\text { blacksheep users, } \\
\text { controversial items, } \\
\text { and niche items. }\end{array}$ \\
\hline $\begin{array}{l}\text { Symeonidis, } \\
\text { et al. [118] }\end{array}$ & $\begin{array}{l}\text { Hybrid Recommendation: Weighted hybrid } \\
\text { recommendations to combine item rating-based similarity } \\
\text { and social structure-based similarity. }\end{array}$ & $\begin{array}{l}\text { RMSE, precision } \\
\text { and recall }\end{array}$ \\
\hline $\begin{array}{l}\text { Victor, et al. } \\
\text { [127] }\end{array}$ & $\begin{array}{l}\text { Nearest Neighbor-based Recommendations: used both } \\
\text { collaborative filtering-based anonymous peers and trust } \\
\text { peers. EnsembleTrustCF (refer to Eq. } 8 \text { ) }\end{array}$ & $\begin{array}{l}\text { MAE, RMSE, } \\
\text { coverage, and } \\
\text { controversial items }\end{array}$ \\
\hline $\begin{array}{l}\text { Wang, et al. } \\
{[132]}\end{array}$ & $\begin{array}{l}\text { Matrix Factorization: Matrix Factorization where latent } \\
\text { factors of a target's friends were combined with the given } \\
\text { target user's latent factors by inner product }\end{array}$ & MAE \& RMSE \\
\hline $\begin{array}{l}\text { Yang, et al. } \\
{[137]}\end{array}$ & $\begin{array}{l}\text { Matrix Factorization: according to categories of } \\
\text { users' rated items, the authors subdivided } \\
\text { users' social links into smaller social network } \\
\text { matrix and trust values within the smaller social } \\
\text { matrix were employed in matrix factorization. }\end{array}$ & MAE \& RMSE \\
\hline $\begin{array}{l}\text { Yuan, et al. } \\
{[142]}\end{array}$ & $\begin{array}{l}\text { Graph Structure-based Recommendation: Target } \\
\text { users' direct and indirect social links were chosen as } \\
\text { social peers using trust propagation distances (i.e. } \\
\text { average path length property of the Epinions.com trust } \\
\text { network) and the graph distance-based weight was } \\
\text { employed to traditional collaboration filtering-based } \\
\text { rating prediction. }\end{array}$ & MAE \\
\hline
\end{tabular}




\begin{tabular}{|c|c|c|}
\hline Approaches & Description of Recommendation Algorithms & $\begin{array}{c}\text { Evaluation } \\
\text { Criteria }\end{array}$ \\
\hline \multicolumn{3}{|c|}{ Friends-based Recommendations } \\
\hline $\begin{array}{l}\text { Bellogín, et } \\
\text { al. [8] }\end{array}$ & $\begin{array}{l}\text { Graph Structure-based Recommendation and } \\
\text { Hybrid Recommendation: 1) recommendations based on } \\
\text { purely users' social networks using Breadth-first Search } \\
\text { algorithm, 2) hybrid recommendations based on } \\
\text { anonymous peers and direct social connections using } \\
\text { feature combination hybridization and 3) hybrid } \\
\text { approach based on Random Walk with Restarts. }\end{array}$ & $\begin{array}{l}\text { Precision, Recall } \\
\text { and NDCG, user } \\
\text { coverage and utility } \\
\text { (the user ratio who } \\
\text { received at least } \\
\text { one correct } \\
\text { suggestion) }\end{array}$ \\
\hline $\begin{array}{l}\text { Bonhard, et } \\
\text { al. }[12,14]\end{array}$ & $\begin{array}{l}\text { Direct Recommendation: Suggested movies rated by } \\
\text { target users' friends with explanations of recommending } \\
\text { friends' identity. }\end{array}$ & $\begin{array}{l}\text { Uptake rates of } \\
\text { recommended } \\
\text { items \& } \\
\text { recommendation } \\
\text { Explanation } \\
\end{array}$ \\
\hline $\begin{array}{l}\text { Carrer-Neto, } \\
\text { et al. [21] }\end{array}$ & $\begin{array}{l}\text { Hybrid Recommendation: Authors generated } \\
\text { recommendations using knowledge base (i.e. movie- } \\
\text { relevant ontology). Then using the weighted hybrid } \\
\text { recommendations, target users' preferences and } \\
\text { preferences of users' friends were combined. }\end{array}$ & $\begin{array}{l}\text { Precision, Recall } \\
\text { and F-Measure }\end{array}$ \\
\hline $\begin{array}{l}\text { De Meo, et al. } \\
\text { [29] }\end{array}$ & $\begin{array}{l}\text { Matrix Factorization: Matrix Factorization that } \\
\text { combined with social distances between target users and } \\
\text { their social links. }\end{array}$ & RMSE \\
\hline $\begin{array}{l}\text { Groh \& } \\
\text { Ehmig [46] }\end{array}$ & $\begin{array}{l}\text { Nearest Neighbor-based Recommendations: } \\
\text { anonymous peers of collaborative filtering were replaced } \\
\text { with users' direct friends. The remaining processes to } \\
\text { calculate user-to-user similarity and computing the } \\
\text { prediction probabilities of candidate items with cosine } \\
\text { similarity are the same with conventional collaborative } \\
\text { filtering }\end{array}$ & $\begin{array}{l}\text { MAE and F- } \\
\text { measure }\end{array}$ \\
\hline $\begin{array}{l}\text { Gürsel and } \\
\text { Sen [49] }\end{array}$ & $\begin{array}{l}\text { Hybrid Recommendation: They inferred categories of } \\
\text { items via users' social tags. Using Bayes Theorem, the } \\
\text { recommender chose items to suggested from the set of } \\
\text { photos posted by target users' friends and to belong to } \\
\text { categories of users' interests. }\end{array}$ & Precision and recall \\
\hline $\begin{array}{l}\text { Jiang, et al. } \\
{[56]}\end{array}$ & $\begin{array}{l}\text { Matrix Factorization: Matrix Factorization combined } \\
\text { with users' reciprocal or unidirectional social networks } \\
\text { and latent topics of items - ContextMF. Item-to-item and } \\
\text { user-to-user similarities were calculated by topic } \\
\text { distributions of items. User-to-user social influence and } \\
\text { the degree of interactions were taken into account, as } \\
\text { well. }\end{array}$ & $\begin{array}{l}\text { MAE, RMSE, } \\
\text { Kendall's ranking } \\
\text { coefficient, } \\
\text { Spearman's rho } \\
\text { and users' } \\
\text { acceptance ratio of } \\
\text { recommended } \\
\text { items. }\end{array}$ \\
\hline $\begin{array}{l}\text { Knijnenburg, } \\
\text { et al. }[63]\end{array}$ & $\begin{array}{l}\text { Nearest Neighbor-based Recommendation: } \\
\text { recommendations based on the similarity between target } \\
\text { users and their friends. Pearson correlations between } \\
\text { every pair of a target user and his friends and the } \\
\text { similarities were aggregated as weight for each candidate } \\
\text { items. }\end{array}$ & $\begin{array}{l}\text { Inspectability (i.e. } \\
\text { transparency), the } \\
\text { feeling of control, } \\
\text { and user } \\
\text { satisfaction }\end{array}$ \\
\hline Konstas, et al. & Graph Structure-based Recommendation: the & Precision \\
\hline
\end{tabular}




\begin{tabular}{|c|c|c|}
\hline Approaches & Description of Recommendation Algorithms & $\begin{array}{c}\text { Evaluation } \\
\text { Criteria }\end{array}$ \\
\hline [65] & $\begin{array}{l}\text { authors built a graph consisting of users, music tracks } \\
\text { and tags as nodes. Social relations along users, users' } \\
\text { music play-counts and frequencies of users' tags were } \\
\text { also considered to add edge weights. Then, they applied } \\
\text { the Random Walk with Restart algorithm to calculate the } \\
\text { preferences of target users for a candidate item. }\end{array}$ & \\
\hline $\begin{array}{l}\text { Liu and Lee } \\
{[76]}\end{array}$ & $\begin{array}{l}\text { Nearest Neighbor-based Recommendations: As the } \\
\text { nearest neighbor groups, anonymous peers of } \\
\text { collaborative filtering were simply combined with target } \\
\text { users' online friends without any additional weight. Then } \\
\text { the traditional nearest neighbor-based recommendation } \\
\text { algorithm was applied with the groups. }\end{array}$ & MAE \\
\hline $\begin{array}{l}\text { Sinha \& } \\
\text { Swearingen } \\
{[111]}\end{array}$ & $\begin{array}{l}\text { Direct Recommendations: Suggested items favored by } \\
\text { target users' friends }\end{array}$ & $\begin{array}{l}\text { Usefulness, } \\
\text { satisfaction of } \\
\text { recommended } \\
\text { items, } \\
\text { trustworthiness of } \\
\text { recommender } \\
\text { system \& various } \\
\text { issues of } \\
\text { recommendation } \\
\text { explanations }\end{array}$ \\
\hline $\begin{array}{l}\text { Wang, et al. } \\
{[130]}\end{array}$ & $\begin{array}{l}\text { Graph Structure-based Recommendations: Random } \\
\text { walk with restart algorithm was applied to one graph } \\
\text { consisting of only target users' direct friends or another } \\
\text { graph consisting of not only target users' direct friends } \\
\text { but also their nearest neighbors whose interests are } \\
\text { similar to the target users but not socially associated. }\end{array}$ & $\begin{array}{l}\text { Precision, recall } \\
\text { and utility }\end{array}$ \\
\hline \multicolumn{3}{|c|}{ Recommendations based on Other Types of Social Networks } \\
\hline $\begin{array}{l}\text { Guy, et al. } \\
{[50]}\end{array}$ & $\begin{array}{l}\text { Nearest Neighbor-based Recommendation: the authors } \\
\text { specified ad-hoc user-to-item weights for users' various } \\
\text { online activities (e.g. authorship of a blog, community } \\
\text { membership, commenting and bookmarking). Then they } \\
\text { multiplied user-to-user relationship strength to the ad-hoc } \\
\text { user-to-item strength with time decay factor. }\end{array}$ & $\begin{array}{l}\text { The degree of } \\
\text { interest and } \\
\text { usefulness of } \\
\text { Recommendation } \\
\text { Explanations }\end{array}$ \\
\hline $\begin{array}{l}\text { Lee \& } \\
\text { Brusilovsky } \\
{[71,74]}\end{array}$ & $\begin{array}{l}\text { Matrix Factorization: the authors built a matrix } \\
\text { factorization only consisting of users' social links }\end{array}$ & Precision and recall \\
\hline $\begin{array}{l}\text { Macedo, et al. } \\
{[82]}\end{array}$ & $\begin{array}{l}\text { Hybrid Recommendation: In order to cope with data } \\
\text { sparsity of the target domain (i.e. events), the authors } \\
\text { consider various kinds of context information such as } \\
\text { group-based social context, event contents, locations of } \\
\text { events, and temporal information of events. }\end{array}$ & $\begin{array}{l}\text { NDCG ranking } \\
\text { Evaluation Metric } \\
\text { (@10) }\end{array}$ \\
\hline $\begin{array}{l}\text { Sun, et al. } \\
{[116]}\end{array}$ & $\begin{array}{l}\text { Matrix Factorization: The authors clustered users' } \\
\text { friends into subgroups and also clustered items into } \\
\text { subgroups according to user-item bookmark/tag } \\
\text { similarities. Then, a subgroup of friends, whose tastes are } \\
\text { similar to target users, and a subgroup of items, which }\end{array}$ & Precision and recall \\
\hline
\end{tabular}




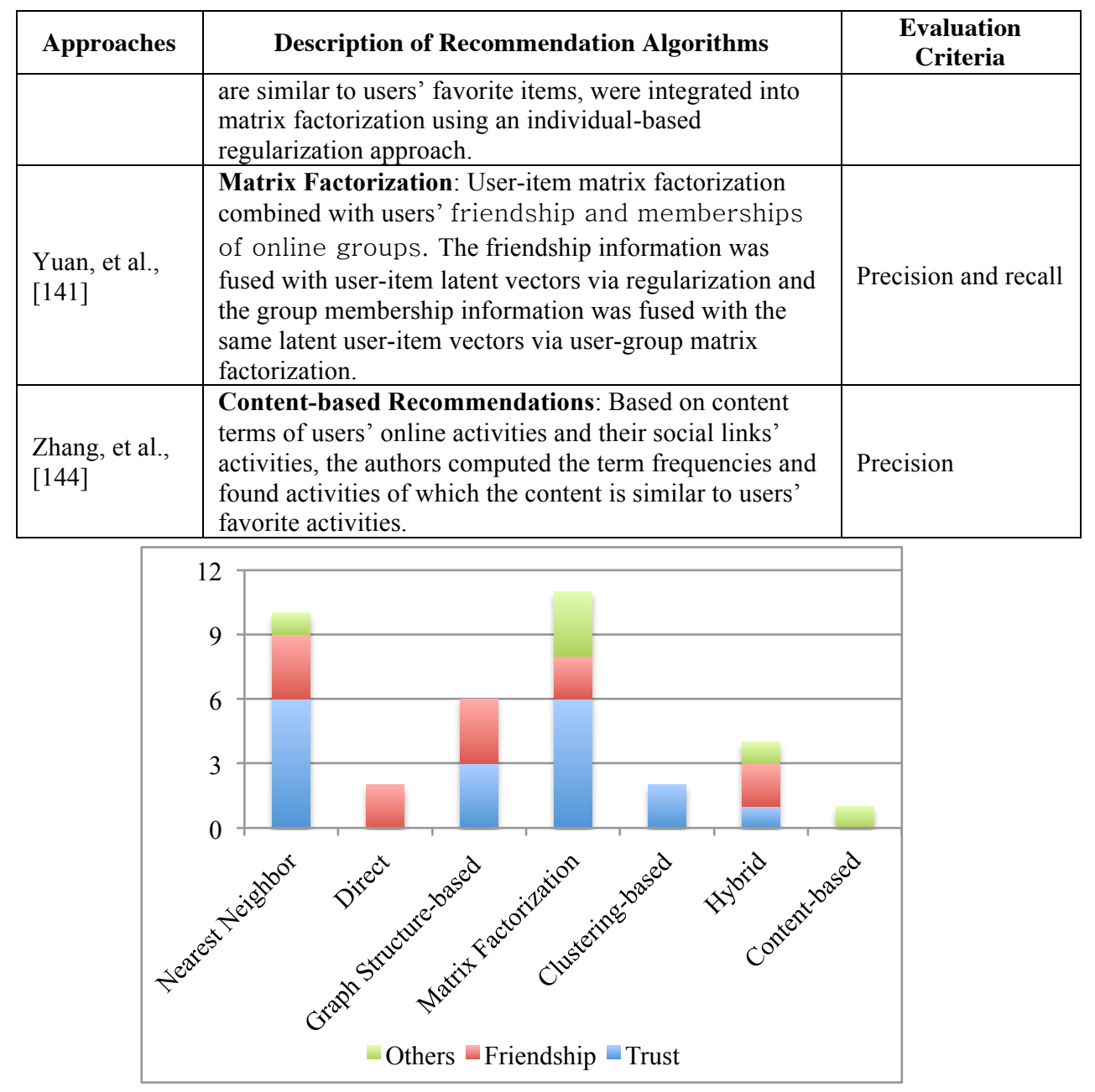

Fig. 12.5. Summary of Various Social Link-based Recommendation Algorithms

For the rest of this chapter, we use the following notations. $R$ is user-item rating matrix, $R \in\left\{R_{u i}\right\}_{l \times n}$ where $n$ and $l$ denote the number of users and items, respectively. $r_{u i}$ is the rating of a item $i$ given by a user $u$. $\hat{r}_{u i}$ denotes the predicted rating of user $u$ for a candidate item $i$, which is picked by recommendation algorithms as presumably favourable item. The range of ratings varies according to the recommender systems: from numeric to unary ratings.

\subsubsection{Direct Friend-to-Friend Recommendations}

As a part of daily interactions with our friends, we share a lot of opinions about everything in our lives; for instance, we recommend our friends a good book to read, 
a reliable mechanic to fix our cars or, ask various opinions ranging from a movie to enjoy, a good restaurant to visit, an e-commerce site to explore and an apparel to buy. Early-generation recommender systems implemented this advice-seeking process and 'word-of-mouth' phenomenon among offline social connections systematically. They enable users to directly send an interesting item to online friends as a recommendation without any systematic computation.

As one of the first related projects, Tapestry allowed users to send items of interest with annotations to their friends and colleagues [45]. Another early project let users directly send interesting research papers to other colleagues using a so-called 'the active push approach' [84]. Dugan and the colleagues also invented an interesting game - 'the Dogear Game' - by borrowing the concept of direct friend-to-friend recommendation. Internet bookmarks were the target item of this game, and given a list of bookmarks, users were asked to guess to whom each bookmark belongs among their colleagues. When users make a right guess, they score a point. Otherwise, while losing game points, they were asked to suggest the corresponding bookmark to the colleague as a recommendation. Even though users incorrectly identified the creator of bookmarks, the authors suggested that there might be a good reason why users believed that the Internet page would interest one of their colleagues making it a good recommendation [35].

In spite of the early efforts, the systems relying on direct exchange of information within a "small world" found it difficult to retain users and to keep them actively contributing to the recommendation process. With these reasons, the conventional collaborative filtering recommendations have employed the "word of mouth" in more extensive and systematic ways. However, as pointed at the Section 12.3.1, it introduced a variety of problems caused by the reliance on anonymous peers and their tastes. The success of social media sites and the abundance of online social networks are the contributing factors making social link-based recommendation to regain the attentions. An advantage of social link-based recommendation over collaborative filtering has been also demonstrated by several studies.

In one of the approaches reviewed on Table 12.3, Sinha and Swearingen [110] compared the users' perceptional difference between machine-generated recommendations and friend-to-friend recommendations. Rather than producing system recommendations using their own algorithms, they relied on recommendations provided by third party applications, Amazon, RatingZones, Reel.com, and MovieCritics. In order to acquire friends' recommendations, the authors asked their participants to provide the names of their three friends who can provide reasonable recommendations to them and suggested items favored by participants' friends. The study revealed that participants found friends' recommendations more useful, satisfying and trustworthy than system-generated recommendations [110]. Bonhard, et al. [12] examined a similar question - whether the perceived familiarity to sources who sent recommendations would affect target recipients' acceptance of the recommendations or not. The authors randomly chose recommendations from either target users' friends or strangers along with information about the senders of the recommendations. Specifically the information about each sender included name, demographic profile (occupations, age, favorite movie genres and hobbies) and overlapped ratings with target user. Through these detailed explanations, the authors tested three factors - 1) personal familiarity to the senders, 2) similarity of 
demographic profiles and 3) rating similarity - on the choice of recommendations. The result showed that users overwhelmingly chose the recommendations from their friends and felt most trustworthy and confident about their choice [12]. Guy and the co-authors [50] obtained similar results in their experiments with recommendations based on professional colleague network.

\subsubsection{Nearest Neighbor-based Recommendation Approach}

The nearest neighbor-based approach consists of three steps: 1) calculating the similarity of a target user to other users in a recommender system, 2) selecting a small set of like-minded "peers", 3) computing the prediction probability of candidate items. For the first step several similarity measures such as Pearson correlation, cosine similarity, Spearman's rank correlation, Jaccard similarity, Log-likelihood similarity, etc. can be used. Pearson correlation (eq. 1) and Cosine similarity (eq. 2) are the most popular in recommendation algorithms.

$$
\begin{gathered}
\operatorname{sim}_{u, v}=\frac{\sum_{j \in I_{u, v}}\left(r_{u j}-\overline{r_{u}}\right)\left(r_{v j}-\overline{r_{v}}\right)}{\sqrt{\sum_{j \in I_{u, v}}\left(r_{u j}-\overline{r_{u}}\right)^{2}} \sqrt{\sum_{j \in I_{u, v}}\left(r_{v j}-\bar{r}_{v}\right)^{2}}} \\
\operatorname{sim}_{u, v}=\frac{\sum_{j \in I_{u, v}} r_{u j} \cdot r_{v j}}{\sqrt{\sum_{j \in I_{u, v}} r_{u j}{ }^{2}} \sqrt{\sum_{j \in I_{u, v} r_{v j}^{2}}^{2}}}
\end{gathered}
$$

In these equations, $\operatorname{sim}_{u, v}$ is the similarity between user $u$ and user $v ; I_{u, v}$ is the set of items co-rated by both user $u$ and user $v ; r_{u}$ and $r_{v}$ are the ratings sets of user $u$ and user $v$, respectively; and $\overline{r_{u}}$ and $\overline{r_{v}}$ are the mean values of the users' rating set. In second step, according to the computed similarities and a threshold value $\theta$, when $u$ 's similarity with $v$ is larger than $\theta$ (i.e. $\operatorname{sim}_{u, v}>\theta$ ), the user $v$ will become one of $u$ 's anonymous peers $\left(v \in N_{u}\right)$.

The last step is to predict missing ratings of candidate items for the target user $u$. Candidate items are favorite items of user $u$ 's peers that are not yet rated by the target user. Eq. 3 shows the equation that is used to predict the user $u$ 's missing rating on a candidate item $j$ (i.e., $\widehat{r_{u j}}$ ), $N_{u j}$ denotes $u$ 's peers who rated the item $j$.

$$
\widehat{r_{u j}}=\overline{r_{u}}+\frac{\sum_{v \in N_{u j}} \operatorname{sim}_{u, v}\left(r_{v j}-\overline{r_{v}}\right)}{\sum_{v \in N_{u j}} \operatorname{sim}_{u, v}}
$$

A natural approach to adapt this nearest neighbor approach to the social recommendation context is to change its second step by using target user's social connections instead of automatically selected similar "peers". Otherwise it is to combine these peers with user's explicitly selected social connections. Among papers reviewed in Table 12.3 and Figure 12.5, ten projects use variants of this idea.

For example, Groh and Ehmig [46] produced friendship-based recommendations by replacing target users' anonymous peers with their friends. In this study to recommend enjoyable Munich-area clubs, whereas collaborative filtering 
recommenders can obtain relatively large number of anonymous peers by changing the threshold $\theta$, the social link-based recommendations have to rely on a relatively lower number of friends. Hence, this study included not only users' direct friends but also their friends of friends as social connections for generating recommendations. The results shows that the social link-based recommendations performed better, especially when the ratings are very sparse, and produced more novel suggestions than conventional recommendations. The highly social context of this study (i.e. local area clubs) was likely a contributing factor of this success, because, when we go to a club, we usually do it in a company of friends [46].

In the studies reviewed in the Table 12.3, authors rarely employ any weights to model links between a target user and her social connections. However, depending on the type of social networks, it could be useful to use weighed connections based on social dynamics or graph theory-based measurements (e.g., the frequency of interactions, clustering coefficient, the degree of betweenness, etc.). In particular, when incorporating trust-based social networks into personalized recommendations, trust values could be used as effective weights to identify the properties of the social connections (i.e. trust or distrust and strong tie vs. weak tie).

As example, Massa and Avesani [86] proposed the use of trust-based networks, instead of anonymous peers, to improve recommendations. In order to secure a sufficient number of trust-based connections, they expanded the scope of trust-based social links beyond directly trusted parties. In the studies based on Epinions.com, the authors explained that the number of user's directly trusted connections (9.88 on average) is much smaller than the number of possible "like-minded" peers (all other users who share common items with target users; 160.73 users on average). Therefore, they included distantly connected users in the trust network (i.e. in $d$ hop distances). However, users of the recommender system assigned trust values only to directly connected parties, and the system does not know how much a target user would trust the users in distant relations. In order to estimate propagated trust values of a target user to indirectly connected users, the authors calculated a trust metric, which is so-called MoleTrust. With the assumption that trust is in binary scale (1 means 'trust' and 0 means 'absence of trust') and trust-based links were expanded up to a predetermined maximum distance $d$, the estimated trust value of a social link in $x$ distance $(d \geq x)$ is $(d-x+1) / d$ as a linear decay operation in propagating trust by distance. Once a group of trust-based users was chosen and the propagated trust values were calculated, in the last step to predict the missing ratings of candidate items, the user-to-user similarity - $\operatorname{sim}_{u, v}$ - was substituted with trust values between target users and their directly or indirectly trusted connections - trust $t_{u, v}$ as noted in eq. 4, where $T_{u j}$ denotes $u$ 's trust-based social links who rated the item $j$ [86].

$$
\widehat{r_{u j}}=\overline{r_{u}}+\frac{\sum_{v \in T_{u j}} \operatorname{trust}_{u, v}\left(r_{v j}-\overline{r_{v}}\right)}{\sum_{v \in T_{u j}} \operatorname{trust}_{u, v}}
$$

The study showed that trust-based recommendations solved cold-start user problem, improved predictions and attenuated the computational complexity [86]. Alsharawneh and Williams used a similar approach while generalizing the trust weights as users' credibility by fusing them with users' expertise [5]. 
Golbeck and the colleagues [42,44,43] introduced another trust-based recommendation approach based on a new trust metric - TidalTrust. While MoleTrust included all trust-based connections that have rated a candidate item and are reachable within a predetermined maximum distance, TidalTrust focused on embracing trustbased links who have the shortest path from a target user. Even within a shortest path a candidate user was not considered as a trust-based connection when trust estimates are below a certain threshold. To be precise, in order to calculate the prediction probability of a candidate item $\mathrm{j}$, the recommender system first performed the Breadth First Search to aggregate the list of raters of item $j$. If none of a target user's direct social links rated the item $j$, the search continued to trust-based links within $x$ hop distance until raters were found. Once raters of item $j$ were found, the recommender system inferred the trust values of raters in $x$ hop distance by aggregating all trust values from a target user's direct links to the raters until $x$ distance and calculating the propagated trust values like the eq. 5 .

$$
\begin{aligned}
\text { trust }_{u w} & =\frac{\sum_{v \in T_{u}} \text { trust }_{u, v} \text { trust }_{v, w}}{\sum_{v \in T_{u}} \text { trust }_{u, v}} \\
T_{u}^{+x} & =\left\{w \mid \text { trust }_{u w} \geq \tau\right\}
\end{aligned}
$$

Here trust $\mathrm{uw}_{\mathrm{uw}}$ denotes the propagated trust value from a target user $u$ to an indirect trust-based connection $w$. Once the trust values were computed, the connections whose estimated trust values were larger than a threshold $\tau$ were selected as the trustbased peer of the user $u$ within $x$ distance, represented as $T_{u}^{+x}$ (refer to eq. 6). Once trust-based peer of the user is chosen and the trust values are calculated, the rating prediction is computed as shown in eq. 7. The experiment with FilmTrust data demonstrated that the use of trust enhanced the quality of recommendations $[42,44,43,120]$.

$$
\widehat{r_{u j}}=\frac{\sum_{w \in T_{u j}^{+x}} \text { trust }_{u, w} r_{w j}}{\sum_{w \in T_{u j}^{+x}} \operatorname{trust}_{u, w}}
$$

The authors of the studies utilizing propagated trust values emphasized the merit of social link-based recommendations in terms of accuracy. However, because of the relatively smaller number of socially connected users, the social link-based approaches might also have lower coverage (the ratio of users who received at least one recommendation) than collaborative filtering. In order to create the synergy effect between two approaches, Victor, et al. [127] introduced EnsembleTrustCF as eq. 8.

$$
\widehat{r_{u j}}=\overline{r_{u}}+\frac{\sum_{v \in T_{u j}} \operatorname{trust}_{u, v}\left(r_{v j}-\overline{r_{v}}\right)+\sum_{v \in N_{u j}} \operatorname{sim}_{u, v}\left(r_{v j}-\overline{r_{v}}\right)}{\sum_{v \in T_{u j}} \text { trust }_{u, v}+\sum_{v \in N_{u j}} \operatorname{sim}_{u, v}}
$$

This approach aimed to use both types of candidates- anonymous "like-minded" peers $\left(N_{u j}\right)$ and trust-based social connections $T_{u j}-$ that rated a candidate item $j$. In cases when a user is connected with a target user through a direct or indirect trustbased link and also belongs to the target user's anonymous peer group, the system just took into account the trust value and ignored the peer similarity weight. According to the experiment using Epinions.com data, the approach of Victor, et al. [127] produced better accuracy than other trust-based recommendation approaches and better 
coverage than collaborative filtering. Moradi and Ahmadian [92] also combined trustbased social connections with anonymous peers at the final stage to choose a list of recommended items.

The idea to modify traditional collaborating filtering by combining user explicit social connections with traditional anonymous peers has been also explored for other types of social links such friendship and professional collaboration networks $[50,63,76]$. For example, in a study based on a Korean online social networking site, Cyworld, Liu and Lee [76] compared recommendations produced by a typical CF approach (based on the nearest neighbors' preferences), social link-based approach (based on friend's preferences), and combined approach (based on the combination of both the nearest neighbors and users' friends). The naïve hybridization of anonymous peers and social connections performed the best [76].

\subsubsection{Recommendation Algorithms based on Matrix Factorization}

Despite of its popularity in commercial systems, the nearest neighbor-based algorithms suffered from sparsity problem that are typical in systems with large number of items and a limited number of ratings given by each user. With sparse userto-item ratings set, it is frequently hard to find users with a sufficient rating overlap who could be considered as users with similar taste. The sparsity problem can degrade the recommendation performance by reducing the number of users who can receive any recommendations (i.e. reduced user coverage). As a solution for the sparsity problem, matrix factorization algorithms have been proposed. While modern collaborative filtering algorithms use a range of approaches including Bayesian belief networks, clustering (e.g. k-means, density-based methods, hierarchical clustering), regression-based approaches, Markov decision processes, latent semantic model, etc. [114], advanced social link-based recommendations predominantly use matrix factorization technologies. Among projects reviewed in Table 12.3, 11 projects or more than $30 \%$ are based on matrix factorization. The general idea of the matrix factorization technologies is to compress a large and noisy user-to-item rating matrix into more dense latent space model. The reduced model is based on latent features of users and items, even though these features are usually hard for a human to interpret. The model is trained and optimized using the existing user-to-item data and later the predicted ratings of users for items are computed using the latent space like the following [66].

$$
\hat{R}=P Q^{T}
$$

where $\hat{R}$ is the matrix of predicted ratings. If $f$ is the number of latent features and there are sets of users $U \in\left\{u_{1}, u_{2}, \ldots, u_{n}\right\}$ and items $I \in=\left\{i_{1}, i_{2}, \ldots, i_{l}\right\}$, matrix $P$ $\in \mathbb{R}^{f \times n}$ represents the connections between users and latent features and matrix $Q$ $\in \mathbb{R}^{f \times l}$ represents connections between items and latent features. In other words, vector $p_{u}$ indicates how much the corresponding user $u$ is interested in the each of the $f$ features, whereas a vector $q_{i}$ shows how much the corresponding item $i$ is associated with each of the $f$ latent features. To learn the matrices $P$ and $Q$ and optimize the model, recommender systems minimizes the sum of squared errors between the existing ratings $R$ and $\hat{R}$ like the following. 


$$
\min _{P, Q} \sum_{u} \sum_{i} W_{u i} \cdot\left(R_{u i}-\hat{R}_{u i}\right)^{2}+\lambda\left(\|P\|_{F}^{2}+\|Q\|_{F}^{2}\right)
$$

$\|\cdot\|_{F}^{2}$ is the Frobenius norm and $\lambda>0$ is the regularization parameter. $W_{u i}$ is the weight indicating that, if user $u$ rated item $i$, the value equals to 1 ; otherwise, equals to 0 . This objective function can find the minimum values using gradient descent methods $[79,136]$.

To systematically analyze recommendation approaches based on matrix factorization, we followed the classifications of Yang et al. [136] and Tang, et al. [119] that distinguish co-factorization methods, ensemble methods and regularization methods.

\section{Co-factorization}

The projects using co-factorization approach collectively factorize user-to-item rating matrix and user-to-user social link matrix. Therefore, in this collective factorization, there are matrices $P$ and $Q$, and additional matrix $S-n \times n$ matrix of user-to-user social links. The authors specifically assume that users' latent feature representation is based on their social links and a user $u$ is represented by a vector in both $P$ and $S$. SoRec [80] proposed by Ma and the colleagues belongs to this group. In building the matrix $S$, the authors substitute the trust values with confidence values of the trust relations, by borrowing local authority and local hub concepts in PageRank. They increased the confidence of trusted relations when a user is trusted by many other users and decreased confidence when a user trusts a lot of other users. In this study, users' social information can be captured like the following.

$$
\hat{S}=P Z^{T}
$$

Where $\hat{S}$ is the predicted social relations and $\mathrm{Z} \in \mathbb{R}^{f \times n}$ is the factor feature matrix. With the assumption that the users' preferences can be learned from both rating and social information (i.e. user latent feature matrix $P$ is used to predict user-to-item matrix $\hat{R}$ and social relation matrix $\hat{S}$ ), the authors minimized the sum of the squared errors using the following objective function.

$$
\begin{gathered}
\min _{P, Q, Z} \sum_{u} \sum_{i} W_{u i} \cdot\left(R_{u i}-\hat{R}_{u i}\right)^{2}+\alpha \sum_{u} \sum_{v \in T_{u}} W_{u v}^{s} \cdot\left(S_{u v}-\hat{S}_{u v}\right)^{2} \\
+\lambda\left(\|P\|_{F}^{2}+\|Q\|_{F}^{2}+\|Z\|_{F}^{2}\right)
\end{gathered}
$$

In this study based on Epinions.com data set and the trust-based social links, $W_{u v}^{s}$ is the social weights indicating that, if a user $u$ trusts another user $v$, it equals to 1 ; otherwise, it equals to 0 , and $T_{U}$ is the set of users whom a user $u$ trusts.

\section{Ensemble Methods}

Ensemble methods aim to predict users' missing ratings using a linear combination of ratings from the users and their social links. Social Trust Ensemble [78] proposed by Ma et al. belongs to this group. In the study, the authors suggested to predict users' ratings using the following equation by including both the target user $u$ 's predicted ratings on the candidate item $i$ and the weighted sum of predicted ratings for the item $i$ 
from all of user $u$ 's social links. The power of social links' ratings on the final prediction for the item $i$ can be controlled by the parameter $\alpha$.

$$
\hat{R}_{u i}^{*}=\alpha P_{u} Q_{i}{ }^{T}+(1-\alpha) \sum_{v \in T_{u}} S_{u v} P_{v} Q_{i}{ }^{T}
$$

In this situation, the training objective function to minimize the sum of the square error can be expressed by the following equation:

$$
\min _{P, Q} \sum_{u} \sum_{i} W_{u i} \cdot\left(R_{u i}-\hat{R}_{u i}^{*}\right)^{2}+\lambda\left(\|P\|_{F}^{2}+\|Q\|_{F}^{2}\right)
$$

\section{Regularization Methods}

Regularization methods attempt to guide the matrix factorization process by keeping users' preferences as close as possible to their friends' preferences. The majority of matrix factorization-based approaches reviewed in Table 12.3 belong to this group - SocialMF [54], Social Regularization [81], CircleCon [137], PWS [132], De Meo's [29] and RSboSN [116]. Social Regularization proposed by Ma, et al. [81] is a regularization method to consider the tastes of target users' friends differently depending on the similarity with the target users.

$$
\begin{gathered}
\min _{P, Q} \sum_{u} \sum_{i} W_{u i} \cdot\left(R_{u i}-\hat{R}_{u i}\right)^{2}+\beta \sum_{u} \sum_{v \in T_{u}} \operatorname{sim}_{u, v} \cdot\left(P_{u}-P_{v}\right)^{2} \\
+\lambda_{1}\|P\|_{F}^{2}+\lambda_{2}\|Q\|_{F}^{2}
\end{gathered}
$$

where $\operatorname{sim}_{u, v}$ is the information similarity between user $u$ and $v$ and the parameter $\beta$ is to control the impact of social information [81]. The study tested two versions of the algorithm by calculating $\operatorname{sim}_{u, v}$ as either vector space similarity or Pearson correlation coefficient (see equation 1). The results showed that the Pearson correlation coefficient was a better choice.

SocialMF [54] incorporated the mechanism of trust propagation in matrix factorization. Based on the social influence theory, the authors suggested that a latent feature vector of a user should be dependent on all latent feature vectors of all his direct neighbors. We can make a target user's latent feature vector dependent on all direct and indirect social links with decay weights for distances between the corresponding target user and his social links by minimizing the following expression after normalizing each row of the social matrix $S$ to 1 [54].

$$
\begin{aligned}
\min _{P, Q, S} \sum_{u} \sum_{i} W_{u i} \cdot\left(R_{u i}-\hat{R}_{u i}\right)^{2}+\lambda\left(\|P\|_{F}^{2}+\|Q\|_{F}^{2}\right) \\
+\beta \sum_{v \in T_{u}}\left\|P_{u}-\sum_{v \in T_{u}} S_{u v} P_{v}\right\|_{F}^{2}
\end{aligned}
$$

CircleCon modified the SocialMF model to take into account the social influence according to item category. In this project based on Epinions.com data, the authors divided users' trust-based social links into sub-networks according to the category of their rated items. Then they trained separate matrix factorization model for each category as the following objective function [137]. 


$$
\begin{gathered}
\min _{P^{C}, Q^{C}, S^{C}} \sum_{u} \sum_{i}\left(R_{u i}^{c}-\hat{R}_{u i}^{c}\right)^{2}+\beta \sum_{v \in T_{u}}\left\|P_{u}^{C}-\sum_{v \in T_{u}} S_{u v}^{C} P_{v}^{C}\right\|_{F}^{2} \\
+\lambda\left(\left\|P^{C}\right\|_{F}^{2}+\left\|Q^{C}\right\|_{F}^{2}\right)
\end{gathered}
$$

\subsubsection{Graph-Based Recommendation Approaches}

While graph-based recommendation approaches have been originally explored for traditional recommendations, they become especially popular in the area of social link-based recommendation because social links could be most naturally represented as a social graph. Among the projects reviewed in Table 12.3, seven studies used various graph-based recommendation algorithms (Bellogín, et al. [8], Deng, et al. [31], Jamali \& Ester [52,53], Konstas, et al. [65], Wang, et al. [130], Yuan, et al. [142]).

Bellogín, et al. [8] suggested a social recommendation approach based on users' friendship network using Breadth-First Search algorithm. As the comparison, the authors also fused users' reviewed item lists with users' friendship network to compute 'Random Walk' and 'Random Walk with Restart'. According to the empirical evaluation, the proposed social recommendations produced more accurate suggestions than conventional CF recommendations and the 'Random Walk' and 'Random Walk with Restart' algorithm [8] (for the detailed information about the 'Random Walk' and 'Random Walk with Restart', refer to [123]).

As a way to integrate two different types of recommendations together - trustbased recommendation and item-based collaborative filtering - Jamali and Ester used a random walk model, so-called 'TrustWalker' $[52,53]$ in the context of Epinions.com data set. Their proposed algorithm starts with random walk on the trust network. Among a target user's directly trusted connections, the algorithm finds raters of a given candidate item. If there is any rater of the item, the rating value is returned; otherwise, the algorithm expands the search to trusted users of the directly trusted links. This process continues recursively until rating values of the candidate is found among a target user's direct and indirect trusted links. However, in order to prevent walking too far in the trust-based network, if directly or indirectly trusted user rated an item which is quite similar to the candidate item and the similarity weighted by the distance is above a certain threshold, the algorithm stops the walking and returned the ratings of similar item [52,53].

In contrast with other random walk-based approaches which literally select the steps of each walk randomly, Deng, et al. [31] proposed a different random walkbased recommendation approach - so-called 'RelevantTrustWalker' - that chooses the next movement according to trust statement and information similarity (i.e. trust relevancy). The information similarity was calculated specifically based on latent vectors computed by matrix factorization. In Konstas, et al. [65] and Wang, et al. [130], the authors expanded the trust network graphs by including additional types of nodes and links. Konstas, et al. [65] used a graph that included not only users' online friends, but also their favorite music and the social tags. The edge value of user-tomusic relations was the play-count numbers of songs and the edge values of users-to- 
tags relations was the frequency of the users' tag usage [65]. Wang, et al. (2013) used a graph having both users' direct friends and their anonymous peers [130]. Both studies [65,130] applied the 'Random Walk with Restart' algorithm' to the constructed graphs.

\subsubsection{Advanced Hybrid Recommendation Approaches}

In spite of the various problems of the conventional collaborative filtering reviewed in the section 12.3.1, its simple but powerful performance still catches a lot of attentions. As one effort to leverage the power of collaborative filtering recommendations while also using benefits of social link-based recommendations, several researchers have explored hybrid recommendation approaches by fusing users' online social links with collaborative filtering. Simple hybrid recommendations are common, some times people prefer to explore more advanced hybrid recommendation approaches. As mentioned before, hybrid

In developing their social link-based recommendation algorithm, Gürsel and Sen [49] emphasized that users have different preferences for their friends on different topics of interests. In the study using by Flickr dataset, Gürsel and Sen classified Flickr photos into ten categories via users' social tags. Specifically, the authors composed topical dictionary of social tags for each category and calculated the probability of how much social tags of an item are associated with each topical dictionary. Then the authors counted how many times a target user commented on his friends' photos, which belong to one of the ten categories, and calculated the probability of the target user liking an item posted by one of his friends using Bayes Theorem. This study interpreted users' comments on photos to mean their interests on the photos; hence they are positive feedbacks. In the empirical evaluations, the performance of the proposed social network-based recommendation algorithm was significantly better than content-based recommendations using users' social tags and random sampling-based recommendations in the perspective of precision and recall [49]. This study contributed to a better understanding of social link-based recommendations by substantiating how to incorporate users' topical preferences on social peers into information personalization.

Several hybrid recommendation studies have fused users' social context with content-focused metadata such as social tags or text descriptors of items. In social media-related studies, especially researchers have paid significant amount of attention on social tags. It is because social tags are usually considered as users' cognitive descriptors about tagged items, form collective intelligence and have a lot of implications for various information access-related tasks.

Guy et al. [50,51] utilized both online social networks and social tags as information source to generate recommendations. In these studies based on a company's social application suite, users are able to manage and share various social media items such as web sites of interests, wiki pages, blogs, files and communities of interests. Users add social tags not only on those social media items but also on other users. As a user's social links, for instance via organization HR chart, bookmarking and social tagging activities, etc., the system gathered various types of links (e.g. friends, colleagues, other users who assigned tags on the same target users, 
commenters of users' bookmarked items, etc.). Social tags that a user assigned on items or were assigned on him by other users were aggregated, as text descriptors about his preference. The results demonstrated that both sources are valuable to increase the quality, to reinforce the diversity and to suggest the explanations about recommendations.

Pera and $\mathrm{Ng}$ [98] introduced a hybrid approach fusing metadata properties of books with users' social context. First in order to choose candidate books to recommend, social tag-based content similarities between the candidate books and target users' favorite books were counted, rather than the similarities of contents derived directly from the books (such as from the titles, abstracts or the authorse names). In the subsequent process, they aggregated the ratings of the candidate items given by target users' friends rated. They also computed how the friends' tastes are similar to target users'. In the experiment using LibraryThing, they contrasted social link-based recommendations with the collaborative filtering recommendations provided by Amazon and content-based recommendations provided by LibraryThing, as baseline. As the result, the quality of the hybrid recommendations combining metadata information and friend relations was better than other two baseline approaches in terms of precisions and ranks.

Carrer-Neto, et al. [21] proposed another type of hybrid recommendation approach rooted on a domain knowledge base and users' social networks. In the study exploring the practice of movie recommendations, various kinds of metadata, such as genre, producer, actor, director, location, award, etc., were considered to build user preference models and when predicting favorable items, the recommender system took into account not only a target user's preference model but also his social links' models. However, exploitation of social links' preferences deteriorated the recommendation quality. This study gave us a hint that users' sociality is not a onesize-fits-all solution for improving all kinds of recommendations, and it is critical to choose a right way to fuse the sociality in personalized recommendations. 


\subsection{Problems and Prospects of Social Recommendations}

\subsubsection{Evaluation of Social Recommendation}

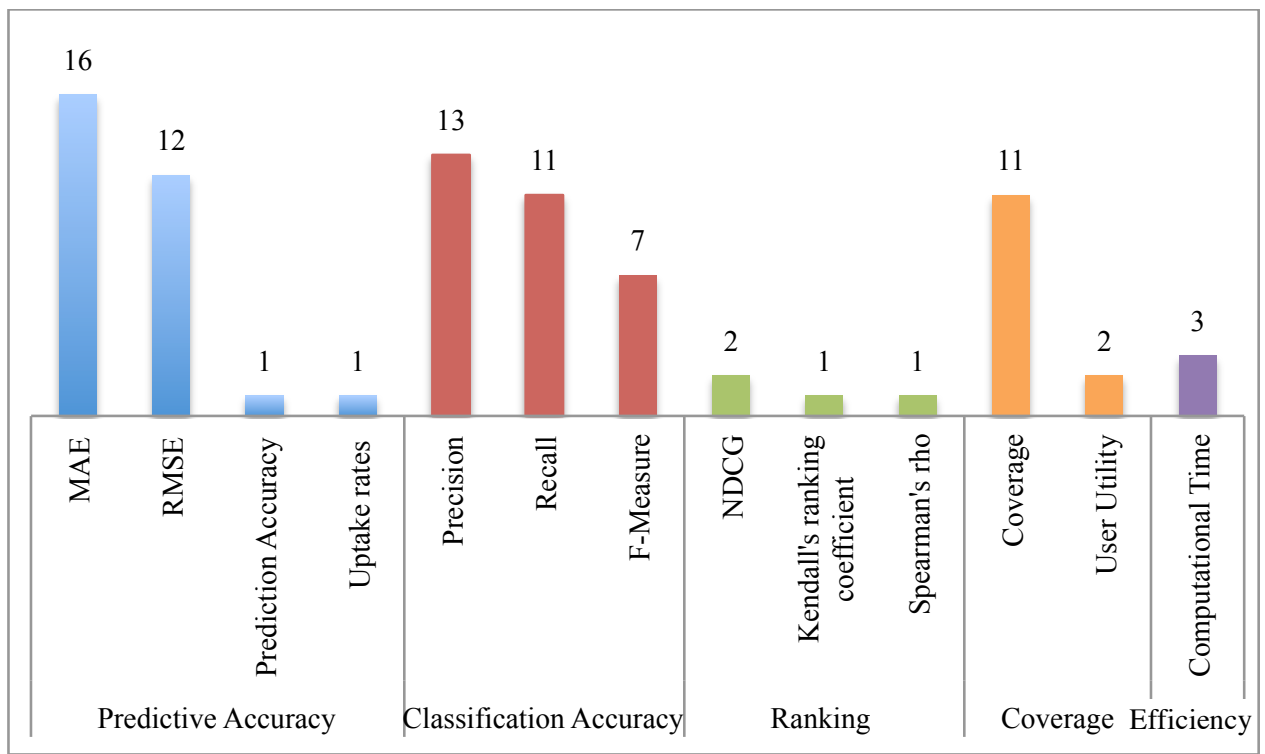

Fig. 12.6. Objective Evaluation Criteria Used in Social Link-based Recommendations

Evaluation is an important aspect of research on recommender systems. A serious attention to evaluation enables the field to prosper and mature through the development of gradually better and more powerful approaches. In this book, a detailed coverage of various approaches used to evaluate recommender systems is offered in Chapter 10 [61]. Instead of duplicating this information, this subsection attempts to provide a brief summary of evaluation approaches used for social linkbased recommendation and to attract attention to a relative lack of user-centered approaches. Figure 12.6 summarizes evaluation criteria used in studies reviewed in Table 12.3. As the figure shows, evaluation of existing social link-based recommendations is predominantly focused on objective quantifiable measures collected through automatic data-driven evaluation. The assessed categories include predictive accuracy (i.e. Mean Absolute Error (MAE), Root Mean Squared Error (RMSE)), classification accuracy (Precision, Recall, F-Measure, etc.), ranking (Spearman's rho, Kendall's coefficient, Normalized Discounted Cumulative Gain (NDCG)), coverage, and efficiency [106]. There are very few efforts to understand users' subjective opinion about social link-based recommendations. In other words, users' prospects in relation to social link-based recommendations are rarely considered. Among the 36 studies reviewed in Table 12.3, only four studies engaged human subjects into evaluation process. In particular, none of the trust-based recommendations was assessed through human subject studies. 
As one of the early efforts, Sinha and Swearingen [111] explored users' subjective and qualitative perceptions of recommendations. To compare the quality of direct friend-to-friend recommendations and machine-generated recommendations, the authors measured various qualitative evaluation criteria including users' psychological burden of efforts to initiate their recommendations (the amount of data users have to input into systems to receive recommendations), time to receive recommendations, perceived usefulness and trustworthiness, and other interfacerelated issues of recommendations and explanations, such as ease of use, navigability, color schemes, etc. In the field of recommender systems, there are a number of commonly recognized subjective quality measures such as novelty, serendipity, confidence [105], perceived usefulness, trustworthiness [101], etc. Unfortunately, there are too few user studies of social link-based recommendations to reliably determine the user-perceived value of these approaches. For instance, one study suggested that social link-based recommendations deliver more novel recommendations than collaborative filtering [46] but another study suggested the opposite [110]. We believe that, the next generation of research on social link-based recommendations should pay more attention to subjective quality evaluation.

There is also an insufficient volume of evaluations that examines to what extent social link-based recommenders address known problems in the field of recommender systems. As reviewed in the section 12.3.1, the work on social recommender systems was motivated to a considerable extent by several weaknesses of traditional collaborative filtering approaches. However, among these weaknesses only cold-start and data sparsity problems have been sufficiently addressed when evaluating social recommenders. For example, Al-sharawneh \& Williams [5], Deng, et al. [31], Jamali \& Ester [52-54], Massa \& Avesani [86], Moradi \& Ahmadian [92] investigated whether their proposed approaches can solve cold-start user problem. Among the projects reviewed in Table 12.3, Moradi \& Ahmadian [92] is the only study which explored a broader variety of problems associated with traditional collaborative filtering including cold-start users, opinionated users, black-sheep users, controversial items and niche items. The authors were able to demonstrate that their social recommendations based on the nearest neighbor approach with the reliability weights calculated by users' trust-based social links succeeded to address these problems.

\subsubsection{Explanations of Social Link-based Recommendations}

An important advantage of recommendation based on social links is a better ability to explain how recommendations are generated and why a specific item is recommended. The ability to understand the recommendation process and individual recommendation has been recently recognized as highly valuable and the work on explaining recommendations emerged into an important stream of research [122]. Considering highly complex mathematical computations and the black-box process of most modern recommendation approaches, in general, it is really hard to deliver reasonable and persuasive explanations. In contrast the very nature of social linkbased recommendations based on users' self-defined social links makes social recommendation relatively easy to explain and comprehend. While at the moment, 
only a fraction of research on social recommendation explore explanation approaches and the value of explanations, it is certainly a promising direction to pursue.

The most natural and explored explanation approach in the area of social linkbased recommendation is connecting each recommended item with the target user's social connections that were used to select it. Bourke and the colleagues [17] executed an experiment to compare users' acceptance of recommendations with or without the explanations about the source of their recommendations. In the study with Facebook users, the authors suggested favorable Movie/TV shows according to the tastes of the participants' online friends. The results showed that participants gave significantly higher ratings, when they could see the sources of their recommendations [17]. The series of works by Bonhard and the co-authors $[12,13]$ and another work by Guy and his team [50] also positively proved that recommendation explanation is a power means to increase user satisfactions and acceptance rate of recommendations.

Knijnenburg, et al. [63] explored a more extensive explanation approach based on an interactive visualization. Main goal of this work was to develop a visualization that the whole process of social recommendation make transparent, explainable, and controllable. It is also to investigate whether users' perceived inspectability and controllability increase positive impressions about their recommendations. In their visual interface that was originally applied for music artist recommendation in Facebook context, the authors used an interactive graph (Figure 12.1) to transparently display the sources of their recommendations to the recipients. The left side graph is target user's favorite artists and by clicking at entities on the graph, the system shows how the recommendations of the right side list generated. For instance, in order to recommend 'Guns N' Roses', 'Nirvana' and 'Avenura' to this target user, the recommender system considered not only target user's tastes about 'Queen', 'Prodigy' and 'Metalica' but also preferences of his friend Zlatina. This transparency of recommendations was designed to increase the inspectability. The authors also enabled controllability by allowing the users to interactively adjust the weight of both, their favorite artists and their friends. The questionnaire-based evaluations with 267 Facebook users showed that both inspectability and controllability have a positive effect on the user experience: increased understandability and improved perception about recommendation quality. Later the authors attempted to generalize this visual recommendation approach applying it to other recommendation areas such as job recommendation [15]. 


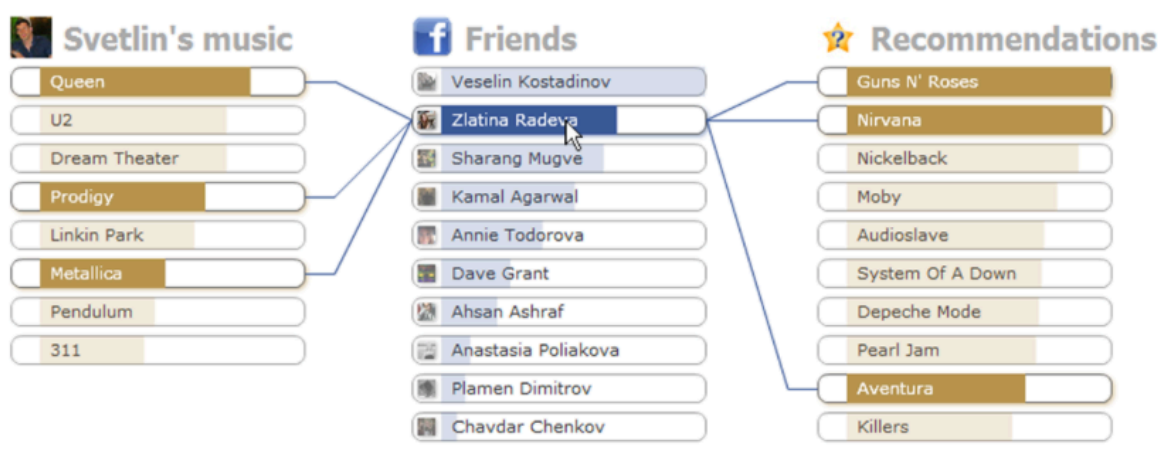

Fig. 12.7. An Interactive Graph Explaining Recommendations using Users' Favorite Information and their Friends [63]

\subsubsection{Cross-system and Multidimensional Online Social Networks}

Due to the explosive popularity of online social networking systems (SNS), users have been enjoying a plethora of online social networks. Even though online users already have been participated in miscellaneous SNSs, unique features and functionalities of newly emerging SNSs entice users into joining another. However, the current teeming SNS market has raised several problems. Along with addiction to SNS, violation of privacy, cyber bullying and spread of malevolent information, there is 'walled garden' problem [139]. The problem indicates that users' profiles and online social network information exclusively exist on one SNS, and are not shared with other systems. Hence, users' online profiles, shared information and social connections are scattered across many different SNSs, and it worsens information glut problem. In order to stay socially active, users have to interact with different subsets of online friends on different SNSs. Even though studies like Subrahmanyam, et al. [115] insisted that online users take advantage of various SNSs to strengthen different aspects of social networks, it evidently makes online users overloaded.

The scattering of online profiles and social networks across several SNSs also cause cold-start user problems. In one system, a user might have diligently established connections and shared interesting information for a considerable time. When she moves to another system, however, all this information collection is ignored and she needs to start again with an empty profile. To cope with this problem, several efforts have been proposed. Vu et al. [128] also introduced an exemplary system to aggregate a variety of users' social data - e.g. users' textual comments, their friends and groups information and online profiles - into one framework and to utilize the gathered data in personalized information filtering or sharing. However, the paper proposed a conceptual framework and did not yet assess the viability of the proposed personalization approach empirically. Even though the main purpose was to recommend friends, not the items of interests, De Meo et al. [29].also focused on the societal nature of human beings where people participate in more than one social network (e.g. a person is a part of his kinship-based networks, friendship-based social networks, professional social networks, etc.). 
As commercial solutions, social network/social data aggregation services - for instance, FriendFeed, Hootsuite, Flock, Postano, Alternion, etc. - are in operation to sweep and organize data spread over multiple SNSs. However, all of these efforts are still in dawning stage. Therefore, it is too early to expect that the aggregated social networks across multiple SNSs have been used in personalizing users' information access. Even so, personalized recommendation based on multi-SNS social networks is a promising and necessary direction to pursue.

On the other hand, existing social link-based recommendation approaches are not quite ready to operate with a variety of links imported from different social links. As shown in the Table 12.1, the majority of existing approaches were developed to work with exactly one type of social links - although similar approaches are sometimes independently explored with different link types. To a large extent, it is related to the lack of datasets and systems that include multiple types of links - with no truly multidimensional data it is hard to evaluate approaches that use more than one link type. However, on several cases, different types of social connections within one system are available, yet frequently ignored in the current work. For instance, a number of social systems including Facebook enable their users to socially associate with other users not only via direct connections (i.e., friendship) but also via membership in the same group. Social media systems also provide users the functionality to separate online social links into multiple sets. Google Plus users, for instance, are able to define their connections as several separate groups such friends, family, acquaintances, colleagues and more. On some social media systems, we can even freely define and name different kinds of our online social links.

As the number of different social links that connect users across social systems as well as within a single system increases, it is becoming more and more important to develop social recommendation approaches that can work with many kinds of social links in parallel. Main problem in this context is the integration of different link types. Let's imagine a situation that our target user A is a friend of another user B and also is in a co-authorship relation with user $\mathrm{C}$. If a social system can use both of these connection types, is it okay to simply use equal weights to both User B and C in order to generate recommendations for user A? Otherwise, how can we put different weights on multiple types of social links on a system so as to gauge target user A's preference? Kazienko, et al. [58] presented an early study of this topic. The authors built multidimensional social networks based on users' various activities on Flickr photo sharing system and used the multidimensional network in personalized recommendation. They established and used five kinds of social connections - one direct social network derived from users' contact list and four indirect object-centered social connections inferred by their behaviors on Flickr (two users added tags on the same items, joined the same group(s), marked one another's photo(s) as their favorite, and commented on the same items.). The value representing the strength of each link was calculated and added separately. This study provided insights on generating personalized recommendations based on multidimensional social networks. 


\subsubsection{Privacy of online social networks}

Due to the cheap and easy communication tools, social media users have enjoyed the opportunities of meeting new friends, expanding online social networks, gaining new and relevant information, propagating their opinions and so on [47]. In order for users to leverage from these values of online social media, they have to provide and gradually expand their personal information in the form of 'user profiles'. Most social media systems ask users to share personally identified or identifiable data including personal histories such as academic or professional affiliations, personal traits and tastes, information preferences, etc. with other users. However, the fun, useful and innovative nature of social media frequently makes the users to ignore various risks about revealing their personal and social information online. Several studies $[47,1,104]$ reported that online users are becoming more and more conscious and protective about their privacy. A study conducted in 2005 [47] used a sample of 4540 users who shared identifiable names, phone numbers, personal images and characteristics (e.g. current residence, dating preferences and relationship status, political views and various interests). Among them, only three users changed their profile visibilities and only $1.2 \%$ of them changed their privacy settings. However, in another study conducted on 2011 [33], 33\% of 1.5 million users changed their profiles as private. Despite of the remarkably increased recognition of privacy among SNS users, there are reportedly some technical leakages out of users' reach like so-called 'silent listeners'. Third-party applications and online advertisers can take advantage of users' profile information without users' explicit consent [112]. Even in cases when a system enables a reliable privacy protection and a user enables it, it is might not sufficient since a user still remains a weakest spot in the system. A striking case reportedly showed how easily online profiles could be compromised. A college student wrote a computer program to send friend request messages systematically to 250,000 American Facebook users, and one third of them accepted the friend requests [57]. It is reasonable to assume that some ill-purposed users could do the same job and access our private information as our pretended online friends. The invaded user profiles can, of course, put users at a variety of risks and attacks [67].

In this book, an extensive treatment of privacy issues in the context of Social Information Access is provided in the Chapter 2 [62]. Main goal of this section is to focus on the issues that specifically connect social recommendations and privacy. Indeed, because social link-based recommendations rely strongly on users' social links to suggest favorable items, it has been recognized that the availability of social link-based recommendations might add additional challenges to the problem of privacy in SNS. For instance, a user shopping history, which is generally hidden even from friends, could be leaked to her friends through social link-based recommendations. Worse, our distrust in some friends (which we might not be eager to reveal) could be leaked out implicitly as a part of the social recommendation process. The issues of privacy in social recommendation are gradually becoming more critical causing some researches to focus on privacy-sensitive recommendation approaches. In some cases social recommendation approaches might have to be modified to ensure a desired level of privacy, in other cases new approaches should be developed to address privacy concerns. A pioneer work of Machanavajjhala et al. [83] investigated the correlation between recommendation accuracy and the degree of 
privacy preservation and substantiated that good and private recommendations are really hard to implement via Wikipedia and Twitter dataset. However, their study aimed to recommend social links to connect, not information items or products.

\subsection{Conclusion}

This chapter focused on a specific information personalization technology in the context of Social Information Access: recommending relevant information items using explicit user-defined social links. Social links is an important kind of socially contributed information and its use for generating recommendation is currently the principal approach to leverage the power of this information for better information access. The goal of this chapter was to provide an extensive overview of current research on social recommendations while specifically emphasizing "how to" issue, i.e., recommendation algorithms. We started with a brief overview of problems associated with traditional collaborative filtering and as well as arguments in favor of using social links for recommendations. We also presented the background rationales about online social dynamics and various branches of social recommendations. We classified and reviewed existing social link-based recommendations according to the kinds of social networks used in recommendations, target applications/data sources, recommendation algorithms, and evaluation criteria. We also reviewed and explained main classes of recommendation algorithms used in social recommendation: direct friend-to-friend recommendations, nearest neighbor recommendations, graph structure-based recommendations, matrix factorization techniques. We also separately reviewed hybrid recommendations that attempt to fuse one or more recommendation approaches with social link-based recommendation. Lastly, we discussed several emergent issues or social recommender systems connecting it with the areas of future research and possible improvements of social recommendations.

\section{References}

1. Acquisti, A., Taylor, C., Wagman, L.: The Economics of Privacy. Journal of Economic Literature 54(2), 442-492 (2016).

2. Akehurst, J., Koprinska, I., Yacef, K., Pizzato, L., Kay, J., Rej, T.: CCR: a contentcollaborative reciprocal recommender for online dating. In: Proceedings of the TwentySecond international joint conference on Artificial Intelligence-Volume Volume Three 2011,pp. 2199-2204. AAAI Press (2011)

3. Akther, A., Kim, H.-N., Rawashdeh, M., El Saddik, A.: Applying Latent Semantic Analysis to Tag-Based Community Recommendations. In: Kosseim, L., Inkpen, D. (eds.) Advances in Artificial Intelligence, vol. 7310. Lecture Notes in Computer Science, pp. 112. Springer Berlin Heidelberg, (2012)

4. Al-Oufi, S., Kim, H.-N., Saddik, A.E.: A group trust metric for identifying people of trust in online social networks. Expert Syst. Appl. 39(18), 13173-13181 (2012)

5. Al-sharawneh, J., Williams, M.: Credibility-aware Web-based Social Network Recommender: Follow the Leader. In: Proceedings of the 2nd ACM RecSys Workshop 
on Recommender Systems and the Social Web, Barcelona, Spain, September 26, 2010 (2010)

6. Arazy, O., Kumar, N., Shapira, B.: Improving Social Recommender Systems. IT Professional 11(4), 38-44 (2009)

7. Baatarjav, E.-A., Phithakkitnukoon, S., Dantu, R.: Group Recommendation System for Facebook. Paper presented at the Proceedings of the OTM Confederated International Workshops and Posters on On the Move to Meaningful Internet Systems: 2008 Workshops: ADI, AWeSoMe, COMBEK, EI2N, IWSSA, MONET, OnToContent + QSI, ORM, PerSys, RDDS, SEMELS, and SWWS, Monterrey, Mexico (2008)

8. Bellogín, A., Cantador, I., Díez, F., Castells, P., Chavarriaga, E.: An empirical comparison of social, collaborative filtering, and hybrid recommenders. ACM Trans. Intell. Syst. Technol. 4(1), 1-29 (2013).

9. Bellogin, A., Parapar, J.: Using graph partitioning techniques for neighbour selection in user-based collaborative filtering. In: Proceedings of the sixth ACM conference on Recommender systems, Dublin, Ireland (2012)

10. Berkovsky, S., Freyne, J.: Group-based recipe recommendations: analysis of data aggregation strategies. In: Proceedings of the fourth ACM conference on Recommender systems, Barcelona, Spain (2010)

11. Bobadilla, J., Ortega, F., Hernando, A., Gutiérrez, A.: Recommender systems survey. Knowledge-Based Systems 46(0), 109-132 (2013).

12. Bonhard, P., Sasse, M.: 'Knowing me, knowing you'-Using profiles and social networking to improve recommender systems. BT Technology Journal 24(3), 84-98 (2006).

13. Bonhard, P., Sasse, M.A., Harries, C.: "The devil you know knows best": how online recommendations can benefit from social networking. In: Proceedings of the 21st British HCI Group Annual Conference on People and Computers: HCI...but not as we know it Volume 1, University of Lancaster, United Kingdom (2007)

14. Bonhard, P., Sasse, M.A., Harries, C.: "The devil you know knows best": how online recommendations can benefit from social networking. In: Proceedings of the 21st British CHI Group Annual Conference on HCI 2007: People and Computers XXI: HCI...but not as we know it - Volume 1, University of Lancaster, United Kingdom (2007)

15. Bostandjiev, S., O'Donovan, J., H, T., Höllerer: LinkedVis: exploring social and semantic career recommendations. In: Proceedings of the 2013 international conference on Intelligent user interfaces, Santa Monica, California, USA (2013)

16. Bothorel, C.C., Lathia, N., Picot-Clemente, R., Noulas, A.: Location Recommendation with Social Media Data. In: Brusilovsky, P., He, D. (eds.) Social Information Access. Springer, Heidelberg (2017)

17. Bourke, S., McCarthy, K., Smyth, B.: Power to the people: exploring neighbourhood formations in social recommender system. In: Proceedings of the fifth ACM conference on Recommender systems, Chicago, Illinois, USA (2011)

18. Breslin, J., Decker, S.: The Future of Social Networks on the Internet: The Need for Semantics. Internet Computing, IEEE 11(6), 86-90 (2007).

19. Brzozowski, M.J., Hogg, T., Szabo, G.: Friends and foes: ideological social networking. In: Proceeding of the twenty-sixth annual SIGCHI conference on Human factors in computing systems, Florence, Italy (2008)

20. Cantador, I., Castells, P.: Group Recommender Systems: New Perspectives in the Social Web. In: Recommender Systems for the Social Web, vol. 32. Intelligent Systems Reference Library, pp. 139-157. Springer Berlin Heidelberg, (2012)

21. Carrer-Neto, W., Hernández-Alcaraz, M.L., Valencia-García, R., García-Sánchez, F.: Social knowledge-based recommender system. Application to the movies domain. Expert Systems with Applications 39(12), 10990-11000 (2012) 
22. Centola, D., González-Avella, J.C., Eguíluz, V.M., San Miguel, M.: Homophily, Cultural Drift, and the Co-Evolution of Cultural Groups. Journal of Conflict Resolution 51(6), 905-929 (2007).

23. Chen, C.C., Wan, Y.-H., Chung, M.-C., Sun, Y.-C.: An effective recommendation method for cold start new users using trust and distrust networks. Information Sciences 224(0), 19-36 (2013).

24. Chen, J., Liu, Y., Li, D.: Dynamic Group Recommendation with Modified Collaborative Filtering and Temporal Factor. International Arab Journal of Information Technology (IAJIT) 13(2) (2016).

25. Chia, P.H., Pitsilis, G.: Exploring the Use of Explicit Trust Links for Filtering Recommenders: A Study on Epinions. com. Information and Media Technologies 6(3), 871-883 (2011).

26. Christensen, I., Schiaffino, S., Armentano, M.: Social group recommendation in the tourism domain. Journal of Intelligent Information Systems 47(2), 209-231 (2016).

27. Chu, S.-C., Kim, Y.: Determinants of consumer engagement in electronic word-of-mouth in social networking sites. International Journal of Advertising 30(1), 47-75 (2011)

28. Crandall, D., Cosley, D., Huttenlocher, D., Kleinberg, J., Suri, S.: Feedback effects between similarity and social influence in online communities. In: Proceeding of the 14th ACM SIGKDD international conference on Knowledge discovery and data mining, Las Vegas, Nevada, USA (2008)

29. De Meo, P., Ferrara, E., Fiumara, G., Provetti, A.: Improving recommendation quality by merging collaborative filtering and social relationships. In: Proceedings of the 11th International Conference on Intelligent Systems Design and Applications (ISDA) (2011)

30. Debnath, S., Ganguly, N., Mitra, P.: Feature weighting in content based recommendation system using social network analysis. In: Proceeding of the 17th international conference on World Wide Web, Beijing, China (2008)

31. Deng, S., Huang, L., Xu, G.: Social network-based service recommendation with trust enhancement. Expert Systems with Applications 41(18), 8075-8084 (2014).

32. Deutsch, M., Gerard, H.: A study of normative and informational social influences upon individual judgement. Journal of Abnormal \& Social Psychology 51(3), 629-636 (1955).

33. Dey, R., Jelveh, Z., Ross, K.: Facebook users have become much more private: A largescale study. In: Proceedings of 2012 IEEE International Conference on Pervasive Computing and Communications Workshops (2012)

34. Diaz-Aviles, E., Drumond, L., Schmidt-Thieme, L., Nejdl, W.: Real-time top-n recommendation in social streams. In Proceedings of the sixth ACM conference on Recommender systems, Dublin, Ireland (2012)

35. Dugan, C., Muller, M., Millen, D.R., Geyer, W., Brownholtz, B., Moore, M.: The dogear game: a social bookmark recommender system. In: Proceedings of the 2007 international ACM conference on Supporting group work, Sanibel Island, Florida, USA (2007)

36. Eirinaki, M., Louta, M.D., Varlamis, I.: A Trust-Aware System for Personalized User Recommendations in Social Networks. IEEE Transactions on Systems, Man, and Cybernetics: Systems 44(4), 409-421 (2014).

37. Ellison, N.B., Vitak, J., Gray, R., Lampe, C.: Cultivating Social Resources on Social Network Sites: Facebook Relationship Maintenance Behaviors and Their Role in Social Capital Processes. Journal of Computer-Mediated Communication 19(4), 855-870 (2014)

38. Fiske, A.P.: The Four Elementary Forms of Sociality: Framework for a Unified Theory of Social Relations. Psychological Review 99(4), 689-723 (1992).

39. Fond, T.L., Neville, J.: Randomization tests for distinguishing social influence and homophily effects. In: Proceedings of the 19th international conference on World wide web, Raleigh, North Carolina, USA (2010)

40. Friedkin, N.E.: Structural Bases of Interpersonal Influence in Groups: A Longitudinal Case Study. American Sociological Review 58(6), 861-872 (1993). 
41. Golbeck, J.: Introduction to Computing with Social Trust. In: Golbeck, J. (ed.) Computing with Social Trust. pp. pp. 1 - 5. Springer, London (2009)

42. Golbeck, J.: Trust and nuanced profile similarity in online social networks. ACM Trans. Web 3(4), 1-33 (2009).

43. Golbeck, J., Hendler, J.: FilmTrust: movie recommendations using trust in web-based social networks. In: Proceedings of Consumer Communications and Networking Conference, pp. 282-286 (2006)

44. Golbeck, J., Hendler, J.: Inferring binary trust relationships in Web-based social networks. ACM Trans. Internet Technol. 6(4), 497-529 (2006).

45. Goldberg, D., Nichols, D., Oki, B.M., Terry, D.: Using collaborative filtering to weave an information tapestry. Commun. ACM 35(12), 61-70 (1992).

46. Groh, G., Ehmig, C.: Recommendations in taste related domains: collaborative filtering vs. social filtering. In: Proceedings of the 2007 international ACM conference on Supporting group work, Sanibel Island, Florida, USA (2007)

47. Gross, R., Acquisti, A.: Information revelation and privacy in online social networks. In: Proceedings of the 2005 ACM workshop on Privacy in the electronic society, Alexandria, VA, USA (2005)

48. Gunes, I., Kaleli, C., Bilge, A., Polat, H.: Shilling attacks against recommender systems: a comprehensive survey. Artificial Intelligence Review 42(4), 767-799 (2014).

49. Gürsel, A., Sen, S.: Producing timely recommendations from social networks through targeted search. In: Proceedings of The 8th International Conference on Autonomous Agents and Multiagent Systems - Volume 2, Budapest, Hungary (2009)

50. Guy, I., Zwerdling, N., Carmel, D., Ronen, I., Uziel, E., Yogev, S., Ofek-Koifman, S.: Personalized Recommendation of Social Software Items Based on Social Relations. In: Proceedings of the 2009 ACM conference on Recommender systems, RecSys '09, New York, NY (2009)

51. Guy, I., Zwerdling, N., Ronen, I., Carmel, D., Uziel, E.: Social media recommendation based on people and tags. In: Proceedings of the 33rd international ACM SIGIR conference on Research and development in information retrieval, Geneva, Switzerland (2010)

52. Jamali, M., Ester, M.: TrustWalker: a random walk model for combining trust-based and item-based recommendation. In: Proceedings of the 15th ACM SIGKDD international conference on Knowledge discovery and data mining, Paris, France 2009, pp. 397-406. ACM (2009)

53. Jamali, M., Ester, M.: Using a trust network to improve top-N recommendation. In: Proceedings of the third ACM conference on Recommender systems, New York, New York, USA (2009)

54. Jamali, M., Ester, M.: A matrix factorization technique with trust propagation for recommendation in social networks. In: Proceedings of the fourth ACM conference on Recommender systems, Barcelona, Spain (2010)

55. Jannacha, D., Lerchea, L., Zanker, M.: Recommending based on Implicit Feedback. In: Brusilovsky, P., He, D. (eds.) Social Information Access. Springer, Heidelberg (2017)

56. Jiang, M., Cui, P., Liu, R., Yang, Q., Wang, F., Zhu, W., Yang, S.: Social contextual recommendation. In: Proceedings of the 21 st ACM international conference on Information and knowledge management, Maui, Hawaii, USA (2012)

57. Jump, K.: A new kind of fame. In: The Columbian Missourian (Jul 21, 2008)

58. Kazienko, P., Musial, K., Kajdanowicz, T.: Multidimensional Social Network in the Social Recommender System. Systems, Man and Cybernetics, Part A: Systems and Humans, IEEE Transactions on 41(4), 746-759 (2011).

59. Kim, H.-N., Rawashdeh, M., Saddik, A.E.: Tailoring recommendations to groups of users: a graph walk-based approach. In: Proceedings of the 2013 international conference on Intelligent user interfaces, Santa Monica, California, USA (2013) 
60. Klein, A., Ahlf, H., Sharma, V.: Social activity and structural centrality in online social networks. Telematics and Informatics 32(2), 321-332 (2015).

61. Kluver, D., Ekstrand, M., Konstan, J.: Rating-Based Collaborative Filtering: Algorithms and Evaluation. In: Brusilovsky, P., He, D. (eds.) Social Information Access. Springer, Heidelberg (2017)

62. Knijnenburg, B.P.: Privacy in Social Information Access. In: Brusilovsky, P., He, D. (eds.) Social Information Access. Springer, Heidelberg (2017)

63. Knijnenburg, B.P., Bostandjiev, S., O'Donovan, J., Kobsa, A.: Inspectability and control in social recommenders. In: Proceedings of the sixth ACM conference on Recommender systems, Dublin, Ireland (2012)

64. Kompan, M., Bielikova, M.: Personalized recommendation for individual users based on the group recommendation principles. Studies in Informatics and Control 22(3), 331-342 (2013).

65. Konstas, I., Stathopoulos, V., Jose, J.M.: On social networks and collaborative recommendation. In: Proceedings of the 32nd international ACM SIGIR conference on Research and development in information retrieval, Boston, MA, USA (2009)

66. Koren, Y., Bell, R.: Advances in Collaborative Filtering. In: Ricci, F., Rokach, L., Shapira, B. (eds.) Recommender Systems Handbook. pp. 77-118. Springer US, Boston, MA (2015)

67. Krishnamurthy, B., Wills, C.E.: On the leakage of personally identifiable information via online social networks. In: Proceedings of the 2nd ACM workshop on Online social networks, Barcelona, Spain (2009)

68. Kutty, S., Chen, L., Nayak, R.: A people-to-people recommendation system using tensor space models. In: Proceedings of the 27th Annual ACM Symposium on Applied Computing, Trento, Italy (2012)

69. Lam, C.: SNACK: incorporating social network information in automated collaborative filtering. In: Proceedings of the 5th ACM conference on Electronic commerce, New York, NY, USA (2004)

70. Lee, D.: How to measure the information similarity in unilateral relations: the case study of Delicious. In: Proceedings of the International Workshop on Modeling Social Media, Toronto, Ontario, Canada (2010)

71. Lee, D., Brusilovsky, P.: Improving Recommendations Using Watching Networks in a Social Tagging System. In: The Proceedings of IConference 2011, Seattle, WA (2011)

72. Lee, D.H., Brusilovsky, P.: Does Trust Influence Information similarity? In: Proceedings of Workshop on Recommender Systems \& the Social Web, the 3rd ACM International Conference on Recommender Systems, New York, NY, USA (2009)

73. Lee, D.H., Brusilovsky, P.: Social Networks and Interest Similarity: The Case of CiteULike. In: Proceedings of the 21th ACM conference on Hypertext and hypermedia, New York, NY, USA, ACM (2010)

74. Lee, D.H., Brusilovsky, P.: Using self-defined group activities for improvingrecommendations in collaborative tagging systems. In: Proceedings of the fourth ACM conference on Recommender systems, Barcelona, Spain (2010)

75. Lee, D.H., Brusilovsky, P., Schleyer, T.: Recommending Collaborators using Social Features and MeSH terms. In: ASIST 2011 Annual Meeting New Orleans, LA, USA (2011)

76. Liu, F., Lee, H.J.: Use of social network information to enhance collaborative filtering performance. Expert Systems with Applications 37(7), 4772-4778 (2010).

77. Lumbreras, A., Gavaldà, R.: Applying Trust Metrics Based on User Interactions to Recommendation in Social Networks. In: Proceedings of the 2012 International Conference on Advances in Social Networks Analysis and Mining (2012) 
78. Ma, H., King, I., Lyu, M.R.: Learning to recommend with social trust ensemble. In: Proceedings of the 32nd international ACM SIGIR conference on Research and development in information retrieval, Boston, MA, USA (2009)

79. Ma, H., King, I., Lyu, M.R.: Learning to recommend with explicit and implicit social relations. ACM Trans. Intell. Syst. Technol. 2(3), 1-19 (2011).

80. Ma, H., Yang, H., Lyu, M.R., King, I.: SoRec: Social Recommendation Using Probabilistic Matrix Factorization. In: Shanahan, J.G., Amer-Yahia, S., Zhang, Y., Kolcz, A., Chowdhury, A., Kelly, D. (eds.) The 17th ACM conference on Conference on information and knowledge management: CIKM '08, Napa Valley, CA, USA (2008)

81. Ma, H., Zhou, D., Liu, C., Lyu, M.R., King, I.: Recommender systems with social regularization. In: Proceedings of the fourth ACM international conference on Web search and data mining, Hong Kong, China (2011)

82. Macedo, A.Q., Marinho, L.B., Santos, R.L.T.: Context-Aware Event Recommendation in Event-based Social Networks. In: Proceedings of the 9th ACM Conference on Recommender Systems, Vienna, Austria (2015)

83. Machanavajjhala, A., Korolova, A., Sarma, A.D.: Personalized social recommendations: accurate or private. Proc. VLDB Endow. 4(7), 440-450 (2011).

84. Maltz, D., Ehrlich, K.: Pointing the way: active collaborative filtering. In: Proceedings of the SIGCHI conference on Human factors in computing systems, Denver, Colorado, United States (1995)

85. Massa, P., Avesani, P.: Trust-aware bootstrapping of recommender systems. In: Proceedings of ECAI 2006 workshop on recommender systems (2006)

86. Massa, P., Avesani, P.: Trust-aware recommender systems. In: Proceedings of the 2007 ACM conference on Recommender systems, Minneapolis, MN, USA (2007)

87. Massa, P., Avesani, P.: Trust Metrics in Recommender Systems. In. Golbeck (ed) Computing with social trust, Springer-Verlag: London, pp. 259-285 (2009)

88. McPherson, M., Lovin, S., Cook, J.: BIRDS OF A FEATHER: Homophily in Social Networks. Annual Review of Sociology 27, 415-445 (2001).

89. Messenger, A., Whittle, J.: Recommendations Based on User-Generated Comments in Social Media. In: Proceedings of the 2011 ieee third international conference on social computing (socialcom), pp. 505-508 (2011)

90. Monge, P.E., Contractor, N.S.: Homophily, Proximity, and Social Support Theories. In: Theories of Communication Networks. pp. 223 - 239. Oxford, New York, NY (2003)

91. Monge, P.E., Contractor, N.S.: Network Concepts, Measures, and the Multitheoretical, Multilevel Analytic Framework. In: Theories of Communication Networks. pp. 29 - 77. Oxford, New York, NY (2003)

92. Moradi, P., Ahmadian, S.: A reliability-based recommendation method to improve trustaware recommender systems. Expert Systems with Applications 42(21), 7386-7398 (2015).

93. Moradi, P., Ahmadian, S., Akhlaghian, F.: An effective trust-based recommendation method using a novel graph clustering algorithm. Physica A: Statistical Mechanics and its Applications 436, 462-481 (2015).

94. Moshfeghi, Y., Piwowarski, B., Jose, J.M.: Handling data sparsity in collaborative filtering using emotion and semantic based features. In: Proceedings of the 34th international ACM SIGIR conference on Research and development in Information Retrieval, Beijing, China (2011)

95. Oh, S., Syn, S.Y.: Motivations for sharing information and social support in social media: A comparative analysis of Facebook, Twitter, Delicious, YouTube, and Flickr. Journal of the Association for Information Science and Technology 66(10), 2045-2060 (2015).

96. Park, M.-H., Park, H.-S., Cho, S.-B.: Restaurant Recommendation for Group of People in Mobile Environments Using Probabilistic Multi-criteria Decision Making Computer- 
Human Interaction. In: Lee, S., Choo, H., Ha, S., Shin, I. (eds.), vol. 5068. Lecture Notes in Computer Science, pp. 114-122. Springer Berlin / Heidelberg, (2008)

97. Pazos Arias, J.J., Fernández Vilas, A., Díaz Redondo, R.P., Groh, G., Birnkammerer, S., Köllhofer, V.: Recommender Systems for the Social Web. In, vol. 32. Intelligent Systems Reference Library, pp. 3-42. Springer Berlin Heidelberg, (2012)

98. Pera, M.S., Ng, Y.-K.: With a Little Help from My Friends: Generating Personalized Book Recommendations Using Data Extracted from a Social Website. In: Proceedings of the 2011 IEEE/WIC/ACM Joint Conference on Web Intelligent (WI'11), Lyon, France (2011)

99. Pitsilis, G., Knapskog, S.J.: Social Trust as a solution to address sparsity-inherent problems of recommender systems. In: Proc. Of ACM RecSys 2009 Workshop on Recommender Systems and the Social Web, New York, New York (2009)

100. Pizzato, L., Rej, T., Akehurst, J., Koprinska, I., Yacef, K., Kay, J.: Recommending people to people: the nature of reciprocal recommenders with a case study in online dating. User Modeling and User-Adapted Interaction, 1-42 (2012).

101. Pu, P., Chen, L., Hu, R.: Evaluating recommender systems from the user's perspective: survey of the state of the art. User Modeling and User-Adapted Interaction 22(4-5), 317355 (2012).

102. Richardson, M., Domingos, P.: Mining knowledge-sharing sites for viral marketing. In: Proceedings of the eighth ACM SIGKDD international conference on Knowledge discovery and data mining 2002, pp. 61-70. ACM (2002)

103. Sanchez, F., Barrilero, M., Uribe, S., Alvarez, F., Tena, A., Menendez, J.: Social and Content Hybrid Image Recommender System for Mobile Social Networks. Mobile Networks and Applications, 1-14 (2012).

104. Saridakis, G., Benson, V., Ezingeard, J.-N., Tennakoon, H.: Individual information security, user behaviour and cyber victimisation: An empirical study of social networking users. Technological Forecasting and Social Change 102, 320-330 (2016).

105. Schaefer, J.B., Frankowski, D., Herlocker, J., Sen, S.: Collaborative Filtering Recommender Systems. In: Brusilovsky, P., Kobsa, A., Nejdl, W. (eds.) The Adaptive Web: Methods and Strateiges of Web Personalization. pp. 291-324. Springer, Berlin, Germany (2007)

106. Shani, G., Gunawardana, A.: Evaluating Recommendation Systems. In: Ricci, F., Rokach, L., Shapira, B., Kantor, P.B. (eds.) Recommender Systems Handbook. pp. 257297. Springer US, (2011)

107. Shardanand, U., Maes, P.: Social information filtering: algorithms for automating "word of mouth". In: Proceedings of the SIGCHI Conference on Human Factors in Computing Systems, Denver, Colorado, USA (1995)

108. Shi, Y., Larson, M., Hanjalic, A.: Towards Understanding the Challenges Facing Effective Trust-Aware Recommendation. In: Proceedings of the 2nd ACM RecSys Workshop on Recommender Systems and the Social Web, Barcelona, Spain (2010)

109. Singla, P., Richardson, M.: Yes, there is a correlation: - from social networks to personal behavior on the web. In: the 17th international conference on World Wide Web, WWW '08, Beijing, China, pp. 655-664. ACM (2008)

110. Sinha, R., Swearingen, K.: Comparing Recommendations Made by Online Systems and Friends. In: DELOS Workshop on Personalisation and Recommender Systems in Digital Libraries, Dublin City University, Ireland (2001)

111. Sinha, R., Swearingen, K.: Comparing Recommendations Made by Online Systems and Friends. In: Proceedings of the DELOS-NSF Workshop on Personalization and Recommender Systems in Digital Libraries (2001)

112. Stutzman, F., Gross, R., Acquisti, A.: Silent listeners: The evolution of privacy and disclosure on facebook. Journal of privacy and confidentiality 4(2), 2 (2013). 
113. Su, X.: Collaborative filtering: A survey. In: 2015 4th International Conference on Reliability, Infocom Technologies and Optimization (ICRITO) (Trends and Future Directions) (2015)

114. Su, X., Khoshgoftaar, T.M.: A survey of collaborative filtering techniques. Advances in artificial intelligence 2009, 4 (2009).

115. Subrahmanyam, K., Reich, S.M., Waechter, N., Espinoza, G.: Online and offline social networks: Use of social networking sites by emerging adults. Journal of Applied Developmental Psychology 29(6), 420-433 (2008).

116. Sun, Z., Han, L., Huang, W., Wang, X., Zeng, X., Wang, M., Yan, H.: Recommender systems based on social networks. Journal of Systems and Software 99, 109-119 (2015).

117. Swamynathan, G., Wilson, C., Boe, B., Almeroth, K., Zhao, B.Y.: Do social networks improve e-commerce?: a study on social marketplaces. In: Proceedings of the first workshop on Online social networks, Seattle, WA, USA (2008)

118. Symeonidis, P., Tiakas, E., Manolopoulos, Y.: Product recommendation and rating prediction based on multi-modal social networks. In: Proceedings of the fifth ACM conference on Recommender systems, Chicago, Illinois, USA (2011)

119. Tang, J., Chang, Y., Liu, H.: Mining social media with social theories: a survey. SIGKDD Explor. Newsl. 15(2), 20-29 (2014)

120. Tang, J., Hu, X., Liu, H.: Social recommendation: a review. Soc. Netw. Anal. Min. 3(4), 1113-1133 (2013)

121. Terveen, L., McDonald, D.W.: Social matching: A framework and research agenda. ACM Trans. Comput.-Hum. Interact. 12(3), 401-434 (2005).

122. Tintarev, N., Masthoff, J.: Effective explanations of recommendations: user-centered design. In: Proceedings of the 2007 ACM conference on Recommender systems, Minneapolis, MN, USA (2008)

123. Tong, H., Faloutsos, C., Pan, J.-Y.: Random walk with restart: fast solutions and applications. Knowledge and Information Systems 14(3), 327-346 (2008).

124. Turner, J.C.: Social influence. Brooks/Cole, Washington, DC, USA (1991)

125. Turner, J.C., Reynolds, K.J.: Self-Categorization Theory. In: Fiske, S.T., Gilbert, D.T., Lindzey, G. (eds.) Handbook of social psychology. vol. v. 2. John Wiley \& Sons, (2010)

126. Victor, P., Cornelis, C., de Cock, M., Cock, M.: Trust Networks for Recommender Systems. In, vol. 4. Atlantis Computational Intelligence Systems, pp. 91-107. Atlantis Press (2011)

127. Victor, P., Cornelis, C., De Cock, M., Teredesai, A.: A Comparative Analysis of TrustEnhanced Recommenders for Controversial Items. In: Proceedings of the 3rd International AAAI Conference on Weblogs and Social Media, San Jose, CA, USA (2009)

128. Vu, X.T., Abel, M.-H., Morizet-Mahoudeaux, P.: A user-centered and group-based approach for social data filtering and sharing. Computers in Human Behavior 51, Part B, 1012-1023 (2015).

129. Wang, H., Li, G., Feng, J.: Group-Based Personalized Location Recommendation on Social Networks. In: Chen, L., Jia, Y., Sellis, T., Liu, G. (eds.) Web Technologies and Applications, vol. 8709. Lecture Notes in Computer Science, pp. 68-80. Springer International Publishing, (2014)

130. Wang, H., Terrovitis, M., Mamoulis, N.: Location recommendation in location-based social networks using user check-in data. Paper presented at the Proceedings of the 21st ACM SIGSPATIAL International Conference on Advances in Geographic Information Systems, Orlando, Florida (2013)

131. Wang, J., Zhao, Z., Zhou, J., Wang, H., Cui, B., Qi, G.: Recommending Flickr groups with social topic model. Information Retrieval 15(3-4), 278-295 (2012).

132. Wang, Z., Yang, Y., Hu, Q., He, L.: An Empirical Study of Personal Factors and Social Effects on Rating Prediction. In: Cao, T., Lim, E.-P., Zhou, Z.-H., Ho, T.-B., Cheung, D., 
Motoda, H. (eds.) Advances in Knowledge Discovery and Data Mining, vol. 9077. Lecture Notes in Computer Science, pp. 747-758. Springer International Publishing, (2015)

133. Wellman, B.: Computer networks as social networks. Science 293(5537), 2031-2034 (2001).

134. Weng, J., Lim, E.-P., Jiang, J., He, Q.: TwitterRank: finding topic-sensitive influential twitterers. In: Proceedings of the third ACM international conference on Web search and data mining, New York, New York, USA (2010)

135. Xu, Y., Guo, X., Hao, J., Ma, J., Lau, R.Y.K., Xu, W.: Combining social network and semantic concept analysis for personalized academic researcher recommendation. Decision Support Systems 54(1), 564-573 (2012).

136. Yang, X., Guo, Y., Liu, Y., Steck, H.: A survey of collaborative filtering based social recommender systems. Computer Communications 41(0), 1-10 (2014).

137. Yang, X., Steck, H., Liu, Y.: Circle-based recommendation in online social networks. In: Proceedings of the 18th ACM SIGKDD international conference on Knowledge discovery and data mining, Beijing, China (2012)

138. Ye, M., Liu, X., Lee, W.-C.: Exploring social influence for recommendation: a generative model approach. In: Proceedings of the 35th international ACM SIGIR conference on Research and development in information retrieval, Portland, Oregon, USA (2012)

139. Yeung, C.-m.A., Liccardi, I., Lu, K., Seneviratne, O., Berners-lee, T.: Decentralization: The future of online social networking. In: In W3C Workshop on the Future of Social Networking Position Papers (2009)

140. Yoon, H., Zheng, Y., Xie, X., Woo, W.: Social itinerary recommendation from usergenerated digital trails. Personal and Ubiquitous Computing 16(5), 469-484 (2012).

141. Yuan, Q., Chen, L., Zhao, S.: Factorization vs. regularization: fusing heterogeneous social relationships in top-n recommendation. In: Proceedings of the fifth ACM conference on Recommender systems, Chicago, Illinois, USA (2011)

142. Yuan, W., Guan, D., Lee, Y.-K., Lee, S., Hur, S.J.: Improved trust-aware recommender system using small-worldness of trust networks. Knowledge-Based Systems 23(3), 232238 (2010).

143. Zhang, F.-G.: Preventing Recommendation Attack in Trust-Based Recommender Systems. Journal of Computer Science and Technology 26(5), 823-828 (2011).

144. Zhang, J., Wang, Y., Vassileva, J.: SocConnect: A personalized social network aggregator and recommender. Information Processing \& Management 49(3), 721-737 (2013).

145. Zhou, X., Xu, Y., Li, Y., Josang, A., Cox, C.: The state-of-the-art in personalized recommender systems for social networking. Artif. Intell. Rev. 37(2), 119-132 (2012).

146. Zhu, S., Chen, J.: E-commerce use in urbanising China: the role of normative social influence. Behaviour \& Information Technology 35(5), 357-367 (2016).

147. Ziqi, W., Ming, Z., Yuwei, T., Wenqing, W., Yuexiang, Z., Ling, C.: Recommendation Algorithm Based on Graph-Model Considering User Background Information. In: Proceedings of 2011 Ninth International Conference on Creating, Connecting and Collaborating through Computing (C5), pp. 32-39 (2011)

148. Zou, J., Fekri, F.: A belief propagation approach for detecting shilling attacks in collaborative filtering. In: Proceedings of the 22nd ACM international conference on Conference on information \& knowledge management, San Francisco, California, USA (2013) 